\title{
Appropriate use criteria in dermatopathology: Initial recommendations from the American Society of Dermatopathology
}

\section{Task Force / Committee Members:}

Claudia I. Vidal ${ }^{1}$ (i) | Eric A. Armbrect ${ }^{2}$ | Aleodor A. Andea ${ }^{3}$ | Angela K. Bohlke ${ }^{4}$ |

Nneka I. Comfere ${ }^{5}$ | Sarah R. Hughes ${ }^{6} \mid$ Jinah Kim $^{7}$ ( ) Jessica A. Kozel ${ }^{8} \mid$ Jason B. Lee ${ }^{9}$ ( ) | Konstantinos Linos ${ }^{10}$ | Brandon R. Litzner ${ }^{11,12}$ ๑) | Tricia A. Missall ${ }^{1}$ () | Roberto A. Novoa ${ }^{7}$ | Uma Sundram $^{13}$ ๑ | Brian L. Swick ${ }^{14} \mid$ Maria Yadira Hurley (Chair) ${ }^{1}$ (ㅇ |

\section{Rating Panel:}

Murad Alam ${ }^{15}$ | Zsolt Argenyi ${ }^{16}$ | Lyn M. Duncan ${ }^{17}$ | Dirk M. Elston ${ }^{18}$ |

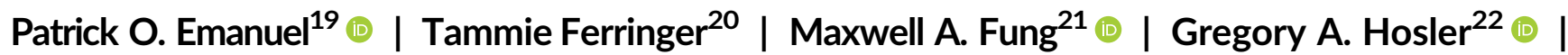

Alexander J. Lazar ${ }^{23}$ (1) | Lori Lowe ${ }^{3}$ | Jose A. Plaza ${ }^{24}$ | Victor G. Prieto ${ }^{23}$ |

June K. Robinson ${ }^{25}$ | Andras Schaffer ${ }^{26}$ | Antonio Subtil ${ }^{27}$ | Wei-Lien Wang ${ }^{28}$

\footnotetext{
${ }^{1}$ Departments of Dermatology and Pathology, Saint Louis University School of Medicine, St. Louis, Missouri

${ }^{2}$ Center for Health Outcomes Research, Saint Louis University, St. Louis, Missouri

${ }^{3}$ Departments of Dermatology and Pathology, University of Michigan Medical Center, Ann Arbor, Michigan

${ }^{4}$ Silver Falls Dermatology, Salem, Oregon

${ }^{5}$ Department of Dermatology and Laboratory Medicine and Pathology, Mayo Clinic, Rochester, Minnesota

${ }^{6}$ Department of Pathology, Gundersen Health System, La Crosse, Wisconsin

${ }^{7}$ Departments of Dermatology and Pathology, Stanford University School of Medicine, Stanford, California

${ }^{8}$ Midwest Pathology Associates, LLC, Overland Park, Kansas

${ }^{9}$ Departments of Dermatology and Cutaneous Biology, Sidney Kimmel Medical College at Thomas Jefferson University, Philadelphia, Pennsylvania

${ }^{10}$ Department of Pathology and Laboratory Medicine, Dartmouth-Hitchcock Medical Center and Geisel School of Medicine at Dartmouth Lebanon, Hanover, New Hampshire
}

The authors Dr. C.I. Vidal, Dr. E.A. Armbrect, Dr. A.A. Andea, Dr. A.K. Bohlke, Dr. N.I. Comfere, Dr. S.R. Hughes, Dr. J. Kim, Dr. J.A. Kozel, Dr. J.B. Lee, Dr. K. Linos, Dr. B.R. Litzner, Dr. T.A. Missall, Dr. R.A. Novoa, Dr. U. Sundram, Dr. B.L. Swick, and Dr. M. Yadira Hurley are members of the Appropriate Use Criteria (AUC) Committee.

The authors Dr. M. Alam, Dr. Z. Argenyi, Dr. L.M. Duncan, Dr. D.M. Elston, Dr. P.O. Emanuel, Dr. T. Ferringer, Dr. M.A. Fung, Dr. G.A. Hosler, Dr. A.J. Lazar, Dr. L. Lowe, Dr. J.A. Plaza, Dr. V.G. Prieto, Dr. J.K. Robinson, Dr. A. Schaffer, and Dr. A. Subtil, Dr. W.-L. Wang are members of the Rating Panel.

Dr. M. Yadira Hurley, as designated, was the Chair of AUC Committee and is the senior author.

The authors Dr. J. Kim, Dr. J.A. Kozel, and Dr. B.R. Litzner, U. Sundram are AUC subgroup lead.

The authors Dr. Z. Argenyi, Dr. L.M. Duncan, Dr. P.O. Emanuel, Dr. T. Ferringer, Dr. M.A. Fung, Dr. G.A. Hosler, Dr. L. Lowe, Dr. J.A. Plaza, Dr. V.G. Prieto, Dr. A. Subtil, and Dr. W.-L. Wang are ASDP representative.

Dr. D.M. Elston was the ASDP President during time of AUC development.

Dr. M. Alam and Dr. J.K. Robinson, are representative of American Academy of Dermatology (AAD).

The authors Dr. A.J. Lazar and Dr. A. Schaffer, are representative of College of American Pathologist (CAP).

Please see related paper on pages [561-562] of this issue. 


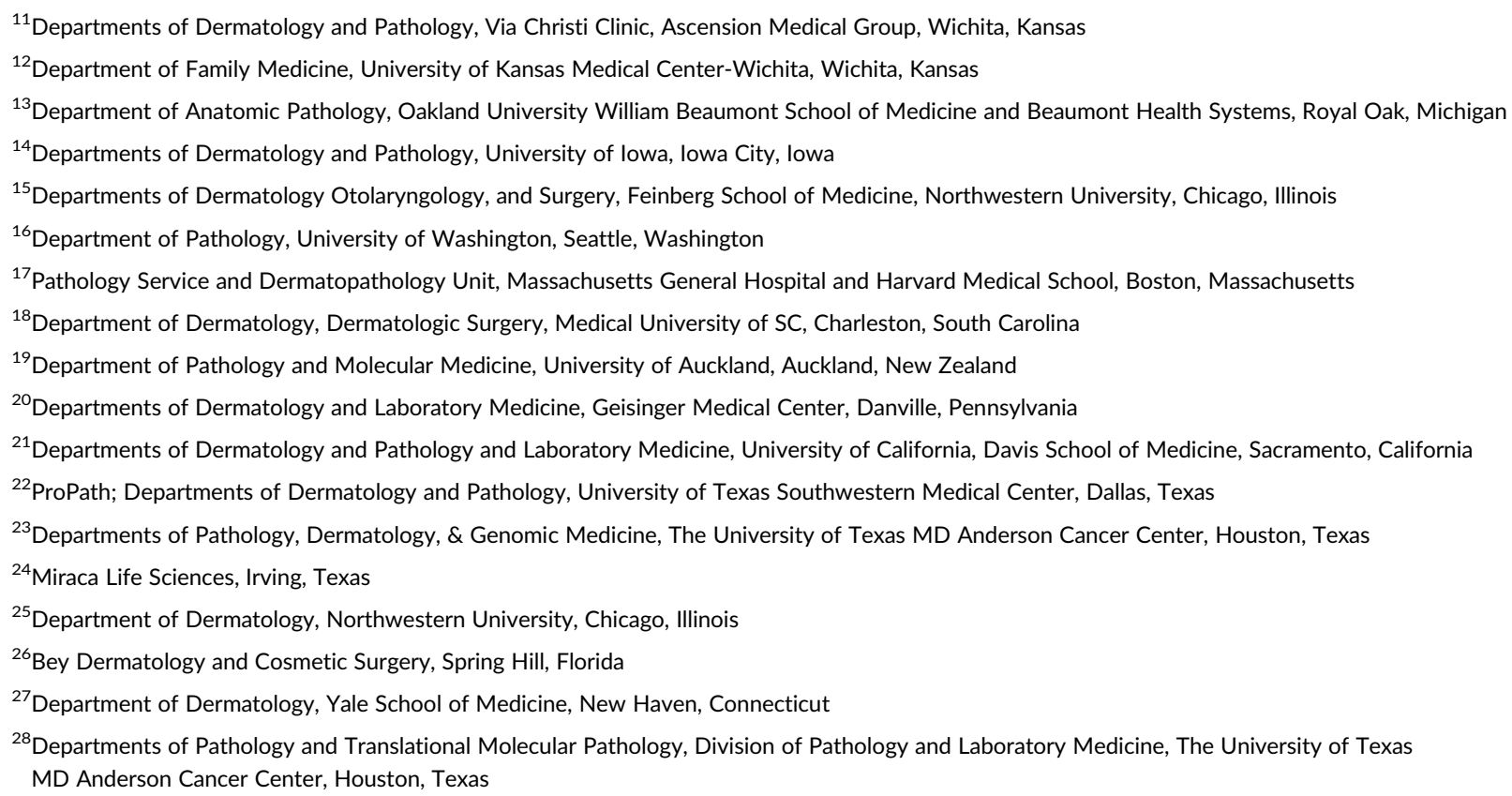

\section{Correspondence}

Claudia I. Vidal, MD, PhD, Departments of Dermatology and Pathology, Saint Louis University School of Medicine, 1755 South Grand Blvd. St. Louis, MO 63104

Email: vidalcmd@gmail.com

Disclaimer The recommendations presented in this study were developed using the RAND Corp methodology (Santa Monica, California)/ University of California-Los Angeles (RAND/ UCLA appropriateness method). Appropriateness ratings represent the best interpretation of the literature combined with expert judgment at the time of their development. The selection of a test ultimately lies with the physician and the assessment of multiple factors associated with the individual patient. The clinical scenarios used should not be considered inclusive of all situations in which a test/study should or can be performed. Future literature may require changes to the recommendations based on additional information.
Background: Appropriate use criteria (AUC) provide physicians guidance in test selection, and can affect health care delivery, reimbursement policy and physician decision-making.

Objectives: The American Society of Dermatopathology, with input from the American Academy of Dermatology and the College of American Pathologists, sought to develop AUC in dermatopathology.

Methods: The RAND/UCLA appropriateness methodology, which combines evidence-based medicine, clinical experience and expert judgment, was used to develop AUC in dermatopathology. Results: With the number of ratings predetermined at 3, AUC were developed for 211 clinical scenarios involving 12 ancillary studies. Consensus was reached for 188 (89\%) clinical scenarios, with 93 (44\%) considered "usually appropriate," 52 (25\%) "rarely appropriate" and 43 (20\%) "uncertain appropriateness."

Limitations: The methodology requires a focus on appropriateness without comparison between tests and irrespective of cost.

Conclusions: The ultimate decision of when to order specific test rests with the physician and is one where the expected benefit exceeds the negative consequences. This publication outlines the recommendations of appropriateness-AUC for 12 tests used in dermatopathology. Importantly, these recommendations may change considering new evidence. Results deemed "uncertain appropriateness" and where consensus was not reached may benefit from further research.

\section{KEYWORDS}

ancillary studies, appropriate use criteria, dermatopathology, evidence-based medicine, expert rating

\section{1 | INTRODUCTION}

Medical leaders and consumers are calling for a safer, more efficient and effective health care system. In recent years, there has been an exponential increase in the number of diagnostic tests. Given the increase in cost from new technologies, physicians need tools to help them make decisions about health care, especially in appropriateness of care, that achieve value, increase quality and control costs. $^{1}$
Appropriate use criteria (AUC) combine the best scientific evidence available with the collective judgment of experts to yield a statement of the appropriateness for performing a test in specific clinical scenarios encountered in everyday practice. Qualifying appropriateness is the first step in addressing cost-effectiveness as studies have shown good correlation between the two. ${ }^{2}$

In 2015, the American Society of Dermatopathology (ASDP) created the AUC Task Force to help guide dermatopathologists in their use of ancillary studies. Four subgroups were established and each 
group chose 2 to 3 ancillary studies for which to develop AUC. The subgroups were divided into 4 broad categories: lymphoproliferative, melanocytic, soft tissue and other.

This report provides a synopsis of the AUC for the ancillary studies chosen by each of the subgroups and developed using the RAND/UCLA appropriateness method. ${ }^{3}$ The goal in a health system is for inappropriate care to be reduced while necessary and appropriate care is increased or maintained. It is imperative to understand that the ancillary studies and clinical scenarios chosen are not exhaustive and that this publication is not a comparison of the different tests as each ancillary study was reviewed independently for each clinical scenario. In addition, as literature emerges updates to the AUC will need to be made and are already planned by the ASDP.

\section{2 | MATERIALS AND METHODS}

The AUC process combines evidence-based medicine with clinical scenarios and expert judgment by engaging a rating panel in a modified Delphi exercise based on the validated appropriateness method of RAND/UCLA to yield a statement regarding the appropriateness of performing a test or procedure in a specific patient scenario. The process begins by selection of tests or procedures for which AUC will be created. In general, AUC focus on tests that are widely and frequently used, consume significant resources or have wide variations in their use. The process overview taken by the ASDP is outlined in (Figure 1).

In total, 12 dermatopathology ancillary studies underwent the AUC process. These include 3 topics for the lymphoproliferative group: T-cell receptor (TCR) clonality assay for the beta chain by polymerase chain reaction (PCR), TCR clonality assay for the gamma chain by PCR and B-cell receptor immunoglobulin heavy chain (IgH) clonality assay by PCR. The melanocytic group also examined 3 topics: fluorescence in situ hybridization (FISH), comparative genomic hybridization $(\mathrm{CGH})$ and gene expression profiling by quantitative reverse transcription polymerase chain reaction ( $q R T-P C R)$ for melanocytic lesions. The other group explored 4 topics: human papillomavirus (HPV) in situ hybridization (ISH; HPV subtypes 6, 11, 16, 18, 31 and 33), HPV immunohistochemistry (IHC; Abcam HPV subtypes 1, 6, 11, 16, 18, 31/Dako HPV subtypes 6, 11, 16, 18, 31, 33, 42, 51, 52,56 and 58) and mismatch repair (MMR) protein IHC 4 antibody panel (MSH2, MLH1, MSH6 and PMS2) and MMR IHC 2 antibody panel (MSH2 and MLH1) in the screening for Muir-Torre syndrome (MTS). Finally, the soft tissue group explored 2 topics: $t(17 ; 22)$ COL1A1-PDGFB FISH assay in the diagnosis of dermatofibrosarcoma protuberans (DFSP) and dual-color break-apart EWSR1 FISH assay in differentiating melanocytic tumors and clear cell sarcoma (CSS).

\subsection{Development of definitions and clinical indications}

Each of the 4 subgroups developed a set of definitions to clearly explain the meaning of assigned terms and histologic diagnoses as well as developed clinical scenarios ("indications") to simulate situations most likely to be encountered in clinical practice. A total of 211 clinical scenarios were produced and then reviewed independently for conciseness and completeness by 12 clinical indication reviewers composed of dermatopathologists from across the country with expertise in various areas. They were then modified accordingly such that they comprised the most often encountered situations in dermatopathology practice. The clinical scenarios were not intended to be exhaustive, but to represent at least $85 \%$ of anticipated scenarios. They were based on information that is readily available to dermatopathologists during routine practice (age, body site, histomorphology, etc.). Further specific information regarding definitions and clinical scenarios for each subgroup is summarized in Tables 1-7. ${ }^{4-9}$

\section{2 | Evidence}

The development of AUC is founded on combining evidence review and analysis with expert judgment that is provided by the panel raters. A detailed literature review was performed by the AUC Task Force to provide the best available evidence on each ancillary study. The 4 subgroups received general guidelines for evidence review including: journal articles written in English, search years beginning in 1940 to 2016, overlapping studies removed and case series with $n>3$ included only if no other evidence was available.

In total, 239 articles were identified and summarized for the development of the literature review tables that were provided to the panel raters for use during rating. Each subgroup added additional parameters if deemed necessary. Synopses of the best scientific evidence for each of the ancillary studies chosen are separately published in the Journal of Cutaneous Pathology. ${ }^{10-14}$

\section{3 | Rating process}

Seventeen panel raters were carefully selected for balance, expertise in a field, and breadth of knowledge. Attempt to avoid selection of panel raters with any financial conflict of interest was made. Twelve panel raters ( 3 per topic) representing a cross section of academicians and private practice physicians were chosen for their expertise in each of the 4 subgroups and then approved by the Chair of the AUC committee. Additionally, there were 2 representatives nominated by the American Academy of Dermatology to incorporate the dermatologists' perspective (both were dermatologists, non-dermatopathologists), 2 representatives nominated by the College of American Pathologists (both were pathologists and dermatopathologists) to incorporate the broader pathology perspective, and a medical director from a regional Medicare carrier. The number of rating rounds was predetermined at 3 . Panel raters received the literature review tables for all of the ancillary studies that included a general summary by test/procedure, concise individual article summaries and the exact citations. They were also provided with clinical scenario booklets. All panel raters rated all of the ancillary studies and all ratings were done independently by each panel rater, with the overarching objective being to converge in consensus. They were instructed to rate the appropriateness of each clinical scenario using their own best expert clinical judgment and the available literature. They were specifically instructed to not consider cost during rating and to rate each test/procedure independently, such that each test/ procedure was rated on its own merits. During each round, panelists 


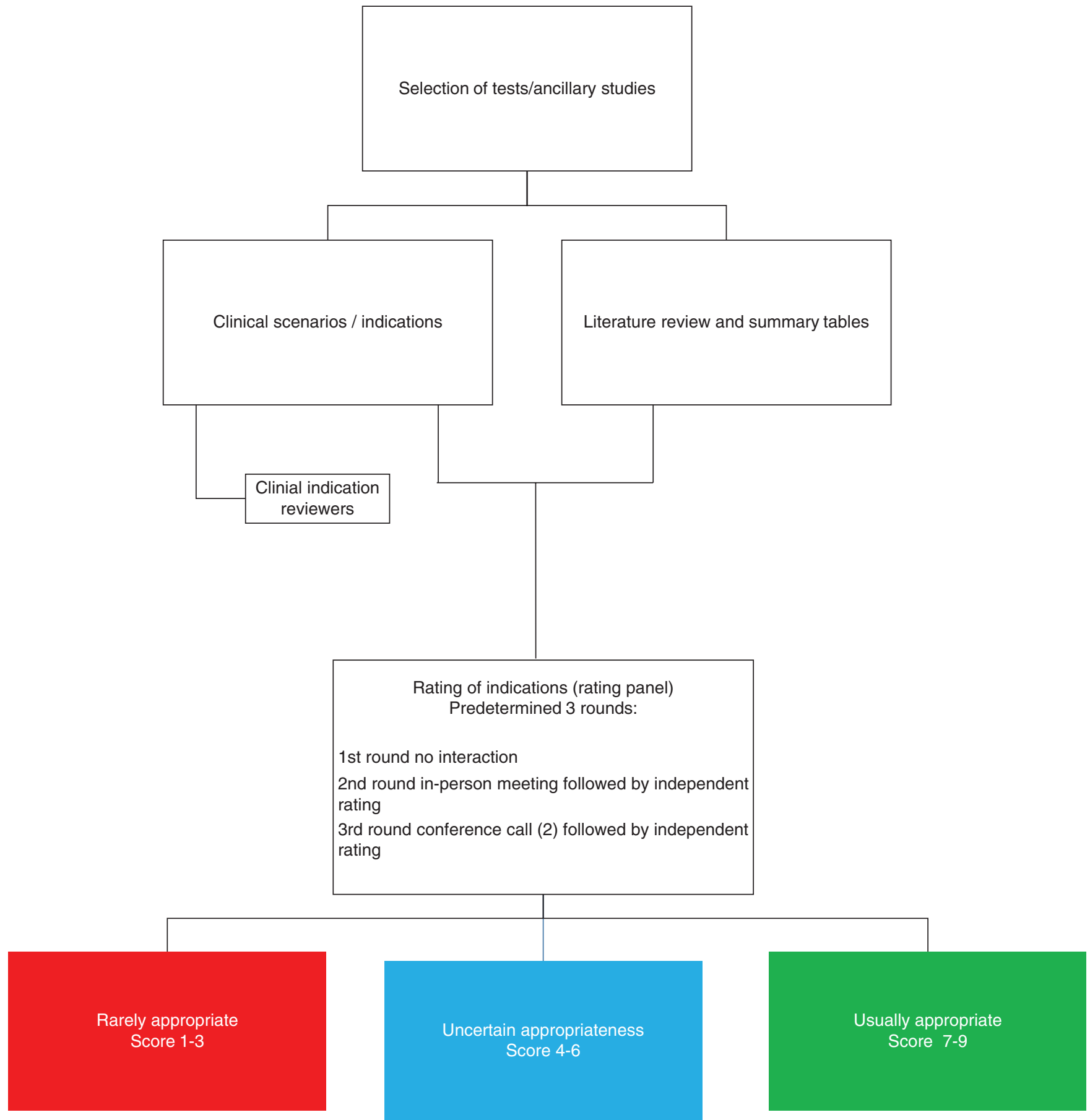

FIGURE 1 Process overview taken by the American Society of Dermatopathology and appropriate use criteria (AUC) Task Force in the development of the dermatopathology AUC

were asked to rate each clinical scenario on a 9-point scale (shown below). A score of 9 to 7 indicated the test/procedure belonged to a category of "usually appropriate" where higher scores indicate greater agreement within the category. A score of 1 to 3 indicated the test/procedure is "rarely appropriate" in that specific clinical scenario while acknowledging clinician discretion may be suitable for ordering the test under selected circumstances. A lower score within the range would indicate strength in conviction of the test being less appropriate. The category nomenclature was chosen to reflect that the ultimate decision to perform a test lies with the physician and takes into account not only the clinical scenario, but also the individual patient. Scores in the rage of 4 to 6 were used to indicate "uncertain appropriateness" for ordering the test/procedure in that clinical scenario. Scores in this midrange generally indicated panel rater's assessment that there was lack of scientific evidence for the test/procedure in general or for that individual clinical scenario. Insufficient scientific evidence could be due to the data being considered as emergent or underdeveloped.

The first-round rating was done individually without interaction with other panel raters or AUC Task Force members. Ratings were analyzed by 2 research team members who identified clinical scenarios where there was no apparent consensus. After the initial rating, an in- 
TABLE 1 Lymphoproliferative definitions and clinical scenarios for T-cell receptor clonality

Definitions:

Specific clinical entities in B-cell and T-cell subgroups categorized according to the 2008 WHO Classification were further examined. ${ }^{4}$

- "Diagnostic for" mycosis fungoides:

- Presence of nearly all typical histopathologic diagnostic features of mycosis fungoides (atypical lymphocytes with hyperchromatic, cerebriform nuclei surrounded by clear haloes, epidermotropism of solitary lymphocytes or clusters of atypical lymphocytes in the absence of spongiosis, epidermal lymphocytes larger than dermal lymphocytes)

- Loss of 1 or more important T-cell marker (CD2, CD5 and/or CD7) within the neoplastic T-cell infiltrate along the dermoepidermal junction and/or in the epidermis

- Nearly all neoplastic cells express CD4 or CD8 (CD4 or CD8 significant predominance)

- "Consistent with" mycosis fungoides:

- Histopathologic diagnostic criteria of mycosis fungoides are present

- Epidermotropic atypical lymphocytes:

- Predominantly immunoreactive for CD2, CD3, CD4, CD5 and CD7 (partial)

- Predominantly immunoreactive for CD4 or CD8

- Loss of 1 or more mature T-cell markers (CD2, CD3, CD5 and CD7)

- "Concerning for," "suspicious of" or "suggestive of" mycosis fungoides:

- Presence of 1 or more typical histopathologic diagnostic features of mycosis fungoides

- Atypical lymphocytes with hyperchromatic, cerebriform nuclei surrounded by clear haloes

- Epidermotropism of solitary lymphocytes or clusters of atypical lymphocytes in the absence of spongiosis

- Epidermal lymphocytes larger than dermal lymphocytes

- Perivascular distribution of atypical lymphocytes ("bare underbelly" sign)

- Papillary dermal fibrosis

- Normal immunophenotypical features: T-cell lymphoid infiltrate along the dermoepidermal junction and/or in the epidermis that is immunoreactive for $\mathrm{CD} 2, \mathrm{CD} 3, \mathrm{CD} 5$ and $\mathrm{CD} 7$ (partial or no loss) with a normal CD4:CD8 ratio

- "Not diagnostic for" mycosis fungoides:

- Limited/minimal/scant T-cell lymphoid infiltrate along the dermoepidermal junction and/or within the superficial dermal perivascular space

- Absence of lymphocyte epidermotropism or folliculotropism

Absence of lymphocyte atypia

- Absence of papillary dermal fibrosis

- Normal immunophenotypical features: T-cell lymphoid infiltrate along the dermoepidermal junction and/or in the epidermis that is immunoreactive for CD2, CD3, CD5 and CD7 (partial or no loss) with a normal CD4:CD8 ratio

- Lymphomatoid papulosis (LyP):

- Wedge-shaped mixed infiltrate of small and large lymphocytes with eosinophils and neutrophils, numerous CD30 positive large lymphocytes

- Or, scant to moderate mixed infiltrate with small and large lymphocytes with epidermotropism

- Or, dense diffuse infiltrate of large atypical CD30 positive lymphocytes

- Pityriasis lichenoides (PL):

- Mixed lichenoid and spongiotic dermatitis with mounds of parakeratosis, extravasated erythrocytes; large cells present

- Or, wedge-shaped superficial and deep dermal lymphocytic infiltrate with extravasated erythrocytes (lymphocytic vasculitis), epidermal necrosis, parakeratosis, lichenoid reaction pattern; large cells present

\section{Clinical scenarios:}

1. Solitary or generalized scaly patches/plaques that are clinically concerning for mycosis fungoides (clinical impression: rule out mycosis fungoides or cutaneous T-cell lymphoma) and that are histologically and immunophenotypically "concerning for", "suspicious of" or "suggestive of" mycosis fungoides."

2. Clinical presentation of erythroderma with clinical impression of rule out mycosis fungoides, cutaneous T-cell lymphoma or Sézary syndrome and that is "not diagnostic for" mycosis fungoides.

3. Clinical presentation of dermatitis with clinical impression of rule out mycosis fungoides or cutaneous T-cell lymphoma and that is "not diagnostic for" mycosis fungoides.

4. Inflammatory/reactive papular or papulonecrotic eruption (solitary, regional or generalized) with clinical impression of LyP or PL, rule out mycosis fungoides or cutaneous T-cell lymphoma and histopathologic and immunophenotypic features typical for LyP or PL.

5. The development of T-cell cutaneous infiltrate that is "not diagnostic for" mycosis fungoides but is present in a patient with a history of mycosis fungoides with a known T-cell clone (comparison of past and present clones).

6. The development of a T-cell cutaneous infiltrate in a patient with a history of systemic T-cell lymphoma.

7. A cutaneous T-cell infiltrate with a folliculotropic rather than epidermotropic T-cell infiltrate.

8. Pigmented purpuric patches (solitary, regional or generalized) and clinical impression of rule out mycosis fungoides or cutaneous T-cell lymphoma and histopathologic and immunophenotypic features that are "not diagnostic for" mycosis fungoides.

9. Clinically reactive entities (see references for individual diagnoses) with histologically and immunophenotypically "concerning for," "suspicious of" or "suggestive of" mycosis fungoides.

10. Preexisting diagnosis of mycosis fungoides and new or evolving lesions similar to original lesions with clinical impression of rule out mycosis fungoides in setting of preexisting mycosis fungoides and histopathologic and immunophenotypic features "consistent with" mycosis fungoides.

11. Development of nodules in a patient with mycosis fungoides which are histologically "concerning for," "suspicious of" or "suggestive of" large cell transformation with CD30 positivity.

12. Development of nodules in a patient with mycosis which are histologically "concerning for," "suspicious of" or "suggestive of" large cell transformation without CD30 positivity.

Abbreviations: PL, pityriasis lichenoides; LyP, lymphomatoid papulosis; WHO, World Health Organization.

person moderated meeting of the panel raters occurred during the 51st annual ASDP meeting (Chicago, 2016). During this meeting, there was a discussion of clinical scenarios where consensus had not been achieved. The discussion was preceded by a literature review summary by an AUC Task Force member for each ancillary study for which AUC were being developed. The goal was to discuss the literature, draw from other experts in the field while also being mindful of not requesting ratings or influencing the panel to seek consensus. After the in-person meeting, the second-round rating was done individually and submitted to the research team within 2 weeks. Prior to the third-round rating, there were 2 moderated teleconference sessions, which focused on clinical scenarios that were close to consensus. Panel raters explored wording of clinical 
TABLE 2 Lymphoproliferative definitions and clinical scenarios for B-cell receptor (IgH) clonality

\section{Definitions:}

Specific clinical entities in B-cell and T-cell subgroups categorized according to the 2008 WHO Classification were further examined. ${ }^{4}$

- "Consistent with" cutaneous marginal zone lymphoma or FCL:

- Histopathologic diagnostic criteria of cutaneous marginal zone lymphoma or FCL are present

- Predominance of B-cells

- B-cells cannot be explained by normal architecture (ie, confined to lymphoid follicles)

- No light chain restriction is present by protein immunohistochemistry (kappa and lambda) or mRNA chromogenic ISH (kappa and lambda)

- "Concerning for," "suspicious of" or "suggestive of" cutaneous marginal zone lymphoma:

- Presence of 1 or more typical histopathologic features of cutaneous marginal zone lymphoma (Grenz zone, predominance of plasma cells, "bottom heavy" infiltrate, superficial and deep perivascular and periadnexal infiltrate, nodular infiltrate with periphery of plasma cells and numerous "monocytoid" B-cells, diffuse infiltrate of monotonous lymphocytes)

- Normal immunophenotypical features (mixed B- and T-cell infiltrate)

- "Concerning for," "suspicious of" or "suggestive of" FCL:

- Presence of 1 or more typical histopathologic features of FCL (Grenz zone, predominance of cleaved cells (centrocytes) and/or large noncleaved cells (centroblasts), nodular infiltrate composed of disorganized follicles, "bottom heavy" infiltrate, follicle-like structures without tingible body macrophages, diffuse infiltrate of monotonous small cleaved or large noncleaved lymphocytes)

- Normal immunophenotypical features (mixed B- and T-cell infiltrate, B-cells confined to follicles, high Ki67 proliferative rate within follicles, lack of Bcl-6+, CD10+ B-cells outside of follicles)

- "Not diagnostic for" cutaneous B-cell lymphoma (cutaneous marginal zone lymphoma or FCL):

- Grenz zone is absent and there is epidermal involvement by lymphocytes

- Scant (less than 200 lymphoid cells) infiltrate

- Minimal number of B-cells within a nodular or diffuse infiltrate

- No light chain restriction as measured by protein immunohistochemistry (kappa and lambda); no light chain restriction as measured by mRNA chromogenic ISH (kappa and lambda)

- "Concerning for," "suspicious of" or "suggestive of" cutaneous diffuse large B-cell lymphoma, leg type:

- Presence of 1 or more typical histopathologic features of large B-cell lymphoma, leg type

- Grenz zone, predominance of large immunoblastic cells

- Diffuse infiltrate, necrosis and easily observable mitotic activity in neoplastic appearing cells

- Predominance of B-cells on immunohistochemistry

\section{Clinical scenarios:}

1. Solitary or multiple erythematous nodules that are clinically concerning for cutaneous B-cell lymphoma (clinical impression-rule out B-cell lymphoma) and that are histologically and immunophenotypically "concerning for," "suspicious of" or "suggestive of" cutaneous marginal zone lymphoma.

2. Solitary or multiple erythematous nodules that are clinically concerning for cutaneous B-cell lymphoma (clinical impression-rule out B-cell lymphoma) and that are histologically and immunophenotypically "concerning for," "suspicious of" or "suggestive of" FCL.

3. Clinical presentation of solitary or multiple nodules with clinical impression of cutaneous lymphoid hyperplasia and that are histologically and immunophenotypically "concerning for," "suspicious of" or "suggestive of" cutaneous marginal zone lymphoma.

4. Clinical presentation of solitary or multiple nodules with clinical impression of cutaneous lymphoid hyperplasia and that are histologically and immunophenotypically "concerning for," "suspicious of" or "suggestive of" FCL.

5. Clinical presentation of solitary or multiple nodules with clinical impression of rule out cutaneous B-cell lymphoma (cutaneous marginal zone or $\mathrm{FCL}$ ) and that is "not diagnostic for" cutaneous B-cell lymphoma.

6. Clinical presentation of a solitary lesion, suggestive of a nonneoplastic process clinically, that has a diffuse infiltrate of lymphocytes and has a predominance of B-cells immunophenotypically.

7. Clinical presentation of a dermatitis, suggestive of a nonneoplastic process clinically, that has a diffuse infiltrate of lymphocytes and has a predominance of B-cells immunophenotypically.

8. Unknown history, but histopathologic and immunophenotypic features "consistent with" cutaneous marginal zone lymphoma or FCL.

9. Preexisting diagnosis of cutaneous B-cell lymphoma (cutaneous marginal zone lymphoma or $\mathrm{FCL}$ ) and new or evolving lesions similar to original lesions with clinical impression of rule out cutaneous B-cell lymphoma and histopathologic and immunophenotypic features "consistent with" cutaneous marginal zone lymphoma or FCL.

10. Solitary or multiple erythematous nodules that are clinically concerning for an aggressive B-cell lymphoma (clinical impression-rule out B-cell lymphoma, leg type) and that are histologically and immunophenotypically "concerning for," "suspicious of" or "suggestive of" cutaneous diffuse large B-cell lymphoma, leg type.

11. The development of a B-cell cutaneous infiltrate that is not diagnostic for cutaneous B-cell lymphoma in a patient with a history of cutaneous B-cell lymphoma with a known B-cell clone (comparison of past and present clones).

12. The development of a B-cell cutaneous infiltrate in a patient with a history of any systemic B-cell lymphoma.

13. Other more aggressive cutaneous B-cell lymphomas other than cutaneous diffuse large B-cell lymphoma, leg type, such as intravascular large B-cell lymphoma or cutaneous plasmablastic lymphoma.

Abbreviations: FCL, follicle center lymphoma; ISH, in situ hybridization; WHO, World Health Organization.

scenarios or definitional understandings that needed clarification. Pane raters were also provided the statistical analysis based on results from the first and second rounds. The third and final ratings were completed individually, again within about 2 weeks of the teleconference sessions. One panelist withdrew from the project after the first round; thus, the complete data for all 3 rounds were provided by 16 panel raters.

To facilitate the panel rater discussion and support categorization for each clinical scenario the mean of ratings was calculated; the mean was adjusted by filtering/removing 2 scores-the highest and lowest-to minimize the impact of outlying raters (mean'). A mean' of $\geq 7.0$ was classified as "usually appropriate." A mean' of $\leq 3.0$ was classified as "rarely appropriate." clinical scenarios with a mean' between 3.1 and 6.9 that had a standard deviation (SD) $\geq 2.0$ were designated as not having reached consensus. It was determined by the research team that a $S D \geq 2.0$ on the 9-point scale captured wide variation in rater scores. The clinical scenarios with a mean' of $\geq 4.0$ and $\leq 6.0$ with a SD $<2.0$ were classified as having reached consensus of "uncertain appropriateness." Clinical scenarios with a SD $<2.0$ with a mean' between 6.1 and 6.9 were classified as "majority usually appropriate" (usually appropriate to uncertain) while those with a mean' between 3.1 and 3.9 were 
TABLE 3 Melanocytic definitions and clinical scenarios

Definitions:

- Nevoid melanoma: lesion of malignant melanocytes with some histologic features which closely mimic architectural and cytologic features of a benign compound or intradermal nevus

- Nevoid cutaneous metastatic melanoma: lesion of metastatic malignant melanoma with some histologic features which closely mimic architectural and cytologic features of a benign compound or intradermal nevus

- Benign melanocytic nevus: lesion of benign melanocytes with either a compound or intradermal configuration

- Atypical blue nevus: lesion of spindled melanocytes with or without an admixed epithelioid component which have any of the following: pronounced cytologic atypia or hyperchromasia, necrosis, increased mitotic rate or dysmaturation

- Blue nevus-like cutaneous metastatic melanoma: lesion of metastatic malignant melanoma composed of spindled and pigmented melanocytes which closely mimic architectural and cytologic features of a benign blue nevus or blue nevus subtype

- Blue nevus-like melanoma (malignant blue nevus): lesion of malignant melanocytes which closely mimic architectural and cytologic features of benign blue nevus or arises within a histologically recognizable benign blue nevus remnant

- Benign blue nevus: lesion of benign spindled melanocytes occurring within a fibrotic stroma, subtypes include cellular, deep penetrating and epithelioid

- Congenital nevus with proliferative nodule: nodular lesion of atypical epithelioid or spindled melanocytes occurring within a preexisting congenital nevus

- Atypical Spitz tumor: lesion of Spitzoid melanocytes which have any of the following: marked architectural asymmetry, dysmaturation, ulceration, increased mitotic rate or increased and/or atypical mitoses in the deep portion of the lesion, marked cytologic atypia

- Incompletely sampled unclassified Spitz tumor: lesion of Spitzoid melanocytes which is partially sampled to the degree it is not able to be subclassified and with atypical features

- Spitzoid melanoma: lesion of malignant melanocytes with some histologic features which closely mimic architectural and cytologic features of a benign Spitz nevus

- Sclerosing (desmoplastic) nevus: lesion of benign melanocytes which may be ovoid, dendritic or Spitzoid occurring within a distinctive eosinophilic stroma with overall architectural symmetry and without significant cytologic atypia or mitotic activity

- Desmoplastic melanoma: lesion of malignant melanocytes with a predominantly spindled shaped, prominent desmoplasia and frequent neurotropism

- Pathology suggestive of/suspicious for melanoma = atypical melanocytic proliferation

- Pediatric patient is $<18$ years of age

- Adult patient is $\geq 18$ years of age

- Fluorescence in-situ hybridization panel includes:

- RREB1 (6p25)

- MYC (8q24)

CDKN2A p16 (9p21)

CCND1 (11q13)

- The 23 genes included in qRT-PCR testing are:

- PRAME a single gene involved in cell differentiation

- S100A7, S100A8, S100A9, S100A12 and PI3, a group of genes involved in multiple cell signaling pathways

- CCL5, CD38, CXCL10, CXCL9, IRF1, LCP2, PTPRC and SELL involved in tumor immune response signaling

- Nine housekeeping genes that are measured to normalize RNA expression for analysis

\section{Clinical scenarios:}

1. Adult patient with pathology definitive for melanoma.

2. Adult patient with pathology suggestive or suspicious for melanoma: nevoid melanoma vs benign melanocytic nevus.

3. Adult patient with pathology suggestive or suspicious for melanoma: nevoid cutaneous metastatic melanoma vs benign melanocytic nevus.

4. Adult patient with pathology suggestive or suspicious for melanoma: melanoma arising within a nevus/dysplastic nevus.

5. Adult patient with pathology suggestive or suspicious for melanoma: atypical blue nevus vs benign blue nevus.

6. Adult patient pathology suggestive or suspicious for melanoma: blue nevus-like cutaneous metastatic melanoma vs benign blue nevus.

7. Adult patient with pathology suggestive or suspicious for melanoma: blue nevus-like melanoma (malignant blue nevus) vs benign blue nevus.

8. Adult with pathology suggestive or suspicious for melanoma: congenital nevus with proliferative nodule vs melanoma.

9. Adult patient with pathology suggestive or suspicious for melanoma: atypical Spitz tumor vs Spitzoid melanoma.

10. Adult patient with pathology suggestive or suspicious for melanoma: incompletely sampled unclassified Spitz tumor vs Spitzoid melanoma

11. Adult patient with pathology suggestive or suspicious for melanoma: sclerosing (desmoplastic) nevus incompletely sampled vs desmoplastic melanoma.

12. Adult patient with pathology suggestive or suspicious for melanoma: severely atypical compound melanocytic proliferation vs melanoma on cosmetically sensitive areas and special sites, including digits, acral, genital, ears and scalp

13. Adult patient with pathology definitive for nevus.

14. Distinction of nevus from primary melanoma in an adult patient when the morphologic findings are ambiguous by light microscopic parameters.

15. Distinction of nevus from primary melanoma in an adult patient when the partial nature of the biopsy precludes optimal assessment by light microscopic parameters.

16. Distinction of nevus from metastatic melanoma in an adult patient when the morphologic findings are ambiguous by light microscopic parameters.

17. Distinction of nevus from metastatic melanoma in an adult patient when the partial nature of the biopsy precludes optimal assessment by light microscopic parameters.

18. Pediatric patient with pathology definitive for melanoma.

19. Pediatric patient with pathology suggestive or suspicious for melanoma: nevoid melanoma vs benign melanocytic nevus.

20. Pediatric patient with pathology suggestive or suspicious for melanoma: nevoid cutaneous metastatic melanoma vs benign melanocytic nevus.

21. Pediatric patient with pathology suggestive or suspicious for melanoma: melanoma arising within a nevus/dysplastic nevus.

22. Pediatric patient with pathology suggestive or suspicious for melanoma: atypical blue nevus vs benign blue nevus.

23. Pediatric patient with pathology suggestive or suspicious for melanoma: blue nevus-like cutaneous metastatic melanoma vs benign blue nevus.

24. Pediatric patient with pathology suggestive or suspicious for melanoma: blue nevus-like melanoma (malignant blue nevus) vs benign blue nevus.

25. Pediatric patient with pathology suggestive or suspicious for melanoma: congenital nevus with proliferative nodule vs melanoma.

26. Pediatric patient with pathology suggestive or suspicious for melanoma: atypical Spitz tumor vs Spitzoid melanoma.

27. Pediatric with pathology suggestive or suspicious for melanoma: incompletely sampled unclassified Spitz tumor vs Spitzoid melanoma.

28. Pediatric with pathology suggestive or suspicious for melanoma: sclerosing (desmoplastic) nevus incompletely sampled vs desmoplastic melanoma.

29. Pediatric patient with pathology suggestive or suspicious for melanoma: severely atypical compound melanocytic proliferation vs melanoma on cosmetically sensitive areas and special sites, including digits, acral, genital, ears and scalp.

30. Pediatric patient with pathology definitive for nevus. 
TABLE 3 (Continued)

31. Distinction of nevus from primary melanoma in a pediatric patient when the morphologic findings are ambiguous by light microscopic parameters.

32. Distinction of nevus from primary melanoma in a pediatric patient when the partial nature of the biopsy precludes optimal assessment by light microscopic parameters.

33. Distinction of nevus from metastatic melanoma in a pediatric patient when the morphologic findings are ambiguous by light microscopic parameters.

34. Distinction of nevus from metastatic melanoma in a pediatric patient when the partial nature of the biopsy precludes optimal assessment by light microscopic parameters.

classified as "majority rarely appropriate" (rarely appropriate to uncertain).

During the in-person meeting, panel raters requested 2 additional options be allowed during the rating process: Unqualified (UQ), which was to be used if "as a dermatopathologist I do not have the expertise to decide if this is appropriate" and OUT, which was not an acronym, but rather an indication that "assessment of appropriateness of test cannot be made without direct communication with the clinician and furthermore the appropriateness will change on a case by case basis depending on the clinical information provided." Panel raters were instructed that these 2 options should be used sparingly.

\section{3 | RESULTS}

A total of 211 clinical scenarios were rated. Consensus was reached for 188 (89\%) scenarios while no consensus was reached for 23 (11\%) scenarios. A consensus of "usually appropriate" was reached in 78 (37\%) scenarios with an additional $15(7 \%)$ scenarios where the majority of ratings were usually appropriate ("majority usually appropriate"), consensus of "rarely appropriated" was reached in 45 (21\%) scenarios with an additional 7 (3\%) scenarios where the majority of ratings were rarely appropriate ("majority rarely appropriate"), while consensus for "uncertain appropriateness" was reached in 43 (20\%) scenarios.

Number of times raters used the options "OUT" and "UQ" was recorded in detail during the third round. Important to note, all panel raters felt they had the expertise to rate all clinical scenarios as "UQ" was never used. The use of the "OUT" rating, indicating that consultation with the clinician may be necessary to determine the appropriateness of ordering the ancillary studies, was considered meaningful if $\geq 3$ panel raters used it and only occurred in a total of 9 clinical scenarios. Scenarios that were rated more than once for separate ancillary tests had complementary "OUT" numbers.

Tables 8-14 summarize appropriateness ratings for each ancillary study by group.

\section{DISCUSSION}

\section{1 | Lymphoproliferative group}

Additional testing is commonly considered when dealing with a cutaneous lymphoid infiltrate. In examining the literature, evidence for the use of T-cell clonality assays was generally more extensive than that for the B-cell clonality assays.

\subsection{1 | TCR clonality assays}

Evidence supports the use of both beta and gamma clonality assays, and is reflected in the results with panel raters ranking the appropriateness of beta and gamma clonality similarly for each scenario. T-cell clonality is recommended as a confirmatory test in cases where the histology and immunophenotype are "concerning," "suspicious" or "suggestive of" MF, if a folliculotropic infiltrate is encountered, and for clone comparison. Interestingly, despite the lack of robust literature, experts still ranked the scenario dealing with a T-cell infiltrate in a patient with a history of T-cell lymphoma as "majority usually appropriate." This may be reflective of the knowledge that in some cases of systemic T-cell lymphomas (ie, angioimmunoblastic T-cell lymphoma), secondary cutaneous infiltrates are often not histologically atypical in appearance. In addition, some specialized immunohistochemical stains (ie, PD-1) are not uniformly available in all laboratories. In these cases, TCR clonality assays may be a rapid and inexpensive way to confirm the diagnosis of secondary cutaneous involvement by systemic T-cell lymphoma. Testing would also be a good approach to cases in which the systemic T-cell lymphoma has the TCR in the germline configuration or if the patient has synchronous primary lymphomas.

Congruent with current scientific evidence, testing is "rarely appropriate" in cases of dermatitis or pigmented purpuric patches with a nondiagnostic histology given the inherent limitations in sensitivity and specificity of clonality tests to reliably distinguish between early presentations of T-cell lymphoproliferative disorders and benign inflammatory dermatoses, such as lymphomatoid drug eruptions, lichen sclerosus, entities within the pityriasis lichenoides disease group, and pigmented purpuric eruptions. The high rate of false positives with clonality testing is reflected in the "rarely appropriate" recommendation for the clinical scenarios in which a diagnosis of lymphomatoid papulosis or pityriasis lichenoides is made histologically and the "uncertain appropriateness" recommendation for clinical reactive entities displaying histology and IHC "concerning," "suspicious" or "suggestive of" MF. Not surprisingly, panel raters felt it was "rarely appropriate" to perform this assay in cases of new nodules in a patient with a known diagnosis of MF "concerning," "suspicious" or "suggestive of" large cell transformation, regardless of CD30 positivity. Surprisingly, there was "no consensus" to perform clonality studies in the scenario of a new or evolving lesion in a patient with a history of MF where the histology and immunophenotype is "consistent with" MF. It may be inferred that in this clinical scenario, it would be more appropriate to compare clones between the current biopsy and the patients' previous biopsies. Ratings also yielded a recommendation of "no consensus" in the scenario of an erythrodermic patient with 
TABLE 4 Other definitions and clinical scenarios for human papillomavirus

Definitions ${ }^{5-7}$ :

- Adult patient: age greater than 14 years

- Pediatric patient: age equal to or less than 14 years

- Condyloma: histopathologic findings to include all of the following: epidermal acanthosis, hyperkeratosis, round parakeratosis, coarse keratohyaline granules, vacuolated keratinocytes, including true koilocytes

- Pathology "suggestive of condyloma": histopathologic findings do not include all of the features defined above for condyloma, and may also include pseudo horn cysts

- Age of 25 was chosen as although seborrheic keratosis have been reported in patients under this age, they are rare and increase in prevalence with increasing age

- Squamous cell carcinoma in situ/ undifferentiated intraepithelial dysplasia of the anogenital skin

- The terminology used for premalignant and malignant dysplasia of the genitourinary tract has been confusing with older terminology including Bowen's disease, erythroplasia of Queyrat, bowenoid papulosis, multifocal Bowen's disease, severe dysplasia and carcinoma in situ

- Newer terminology in the vulva has been replaced with "undifferentiated usual type of vulvar intraepithelial neoplasia (VIN)." This is defined as atypia involving $2 / 3$ to full thickness of the epidermis (previously defined as VIN2 and VIN 3, respectively). VIN1 is not regarded as flat condyloma

- The terminology is likewise confusing on the penis, with some proposing a similar nomenclature-undifferentiated PelN

- Histologically undifferentiated intraepithelial neoplasia (VIN3 and PeIN3) shows full thickness cytologic atypia, increased mitotic figures and dyskeratosis. It can have the presence of hypergranulosis +/- partially vacuolated cells

- SCC of genital skin

- For this purpose, divided into SCC arising in the background of a chronic dermatoses (ie, LSEA and LP or SCC arising in a background of undifferentiated VIN or PeIN

- Various histologies have been reported with some including verrucous carcinoma and others offering a more complex separation with the introduction of terms such as warty (condylomatous) squamous cell carcinoma, papillary squamous cell carcinoma and low-grade verrucous carcinoma

- Verrucous carcinoma:

- The term used here encompass verrucous carcinoma, well differentiated epidermoid squamous cell carcinoma, epithelioma cuniculatum and giant condyloma of Buschke-Löwenstein that clinically present as a warty, exophytic plaque in the oropharynx, lower limb (typically sole of foot) and anogenital region, respectively.

- Histopathologic findings should include all the following: exo-endophytic architecture, hyperkeratosis, keratinocytes w/ abundant pale pink cytoplasm, large bulbous rete ridges with pushing boarder

- Subungual wart includes clinical lesions involving the hyponychium, distal nail bed or proximal nail fold that may be causing subungual hyperkeratosis or onycholysis and have histologic findings that include parakeratosis, papillomatosis and the presence of koilocytes in the most superficial layers.

- Verrucous features defined as having any of the following histologic features: epidermal papillomatosis, coarse keratohyaline granules and vacuolated keratinocytes

- HPV-induced lesion of the genital skin includes condyloma or undifferentiated intraepithelial neoplasia

\section{Clinical scenarios:}

1. Adult patient, pathology definitive for condyloma.

2. Adult patient, pathology suggestive of condyloma.

3. Pediatric patient, pathology definitive for condyloma.

4. Pediatric patient, pathology suggestive of condyloma.

5. Patient under 25 years of age with pathologic findings consistent with seborrheic keratosis of genital skin, perineum, lower abdomen or inner thighs.

6. Patient with squamous cell carcinoma in situ/undifferentiated intraepithelial dysplasia of the genital skin.

7. Patient with a squamous cell carcinoma in the genital area.

8. Patient with a history of an HPV-induced lesion and a squamous cell carcinoma in the genital area

9. Patient with a squamous cell carcinoma in the genital area and a history of chronic dermatoses (ie, LSEA and LP).

10. Patient with clinical impression and pathology consistent with verrucous carcinoma.

11. Patient with a subungual wart.

12. Patient with nail bed, periungual or nail matrix squamous cell carcinoma in situ/squamous cell carcinoma

13. Patient with squamous cell carcinoma in situ or squamous cell carcinoma with verrucous features on digits.

14. Immunosuppressed patients (eg, organ transplant and HIV patients) with squamous cell carcinoma in situ or squamous cell carcinoma with verrucous features.

Abbreviations: LP, lichen planus; LSEA, lichen sclerosus et atrophicus; PeIN, penile intraepithelial neoplasia; SCC, squamous cell carcinoma.

nondiagnostic histology, which may in general reflect poor global experience with early Sézary syndrome.

Although there was 1 clinical scenario where panel raters utilized the "OUT" option during the rating process for both the beta and gamma clonality assays, this was considered to not be significant as rating was completed by $88 \%$ of panel raters.

\subsection{2 | IgH clonality assay}

In looking at the results for B-cell clonality assays, there were 6 clinical scenarios where testing for the rearrangement of the B-cell receptor (IgH) by PCR was "usually appropriate." It is not surprising that testing was found to be "usually appropriate" for scenarios when the histology and immunophenotype of the infiltrate was "concerning 
TABLE 5 Other definitions and clinical scenarios for Muir-Torre syndrome

\section{Definitions ${ }^{8,9}$ :}

- Age 60: there are some articles that suggest age 50 instead of 60 as a cut off, this may be because sebaceous neoplasms present at a mean age of 53

- MTS-associated sebaceous neoplasm: sebaceous adenoma, sebaceoma, sebaceous epithelioma and sebaceous carcinoma

- MTS-associated neoplasm: MTS-associated sebaceous neoplasms, cystic sebaceous neoplasm, basal cell carcinoma with sebaceous differentiation and keratoacanthoma with sebaceous differentiation

- MTS-associated visceral malignancy: colorectal adenocarcinoma (most common), genitourinary carcinoma (second most common), breast, hematologic and endometrial and gastric carcinoma (less common)

\section{Clinical scenarios:}

1. A patient over the age of 60 with a periocular sebaceous carcinoma.

2. A patient over the age of 60 with a single sebaceous tumor on the head and neck.

3. A patient over the age of 60 with a single sebaceous tumor on a site other than the head and neck.

4. A patient over the age of 60 with multiple (greater than or equal to 2 ) sebaceous tumors.

5. A patient over the age of 60 with a basal cell carcinoma with sebaceous differentiation.

6. A patient over the age of 60 with a keratoacanthoma with sebaceous differentiation.

7. A patient over the age of 60 with a cystic sebaceous neoplasm.

8. A patient over the age of 60 with an MTS-associated neoplasm and/or a personal history of an MTS-associated visceral malignancy.

for," "suspicious of" or "suggestive of" either primary cutaneous marginal zone lymphoma (PCMZL) or follicle center lymphoma (FCL). These entities tend to be difficult to diagnose based primarily on histology or immunohistochemistry. In PCMZL, definitive diagnosis often relies on detection of light chain restriction which can be difficult unless plasma cells are abundant. In FCL, the typical histologic features relied on by hematopathologists such as back-to-back follicle formation or bcl-2 expression are often absent even in grade 2 FCL. While in FCL with a diffuse pattern, the presence of sheets of B-cells is concerning for lymphoma, again, lack of typical follicular lymphoma markers such as expression of CD10 and bcl-2 can lead to confusion even among experienced dermatopathologists. In these scenarios, testing with clonality assays can confirm the diagnosis. ${ }^{9}$ As expected, testing was "usually appropriate" in cases where the clonality assay was being used for clone comparison. Testing was recommended by the majority of panel raters in cases where the clinical impression was of a single lesion suggestive of a nonneoplastic process or of dermatitis, but the histology showed a B-cell predominant infiltrate. Conversely, there were 2 clinical scenarios ranked "rarely appropriate": when single or multiple nodules are found and the clinical impression is rule out B-cell lymphoma (PCMZL or FCL), but the histology and immunohistochemistry results are "not diagnostic" for cutaneous B-cell lymphoma; and in patients with a preexisting diagnosis of cutaneous B-cell lymphoma (either PCMZL or FCL) and when a diagnosis of PCMZL or FCL can be made on histologic grounds. There was "no consensus" for 2 scenarios, which included cases where the history is unknown, but the histology and immunophenotype of the infiltrate are "consistent with" with PCMZL or FCL and when other more aggressive cutaneous B-cell lymphomas other than primary cutaneous large B-cell lymphoma,
TABLE 6 Definitions and clinical scenarios for dermatofibrosarcoma protuberans

\section{Definitions:}

- Typical histomorphology of DFSP: monotonous spindled cells in a storiform pattern with "honeycombing" or entrapment of adnexal structures and/or adipocytes and extension into the subcutis

- Nontypical histomorphology of DFSP refers to variant histomorphology such as fibrosarcomatous, giant cell fibroblastoma, myxoid, epithelioid or nonspecific spindled cell histomorphology.

\section{Clinical scenarios:}

1. Tissue with sampling down to subcutis with typical histomorphology of dermatofibrosarcoma protuberans and CD34+ by immunohistochemistry.

2. Tissue with sampling down to subcutis with typical histomorphology of dermatofibrosarcoma protuberans and CD34 immunohistochemistry not uniformly reactive.

3. Tissue with sampling down to subcutis with nontypical histomorphology of dermatofibrosarcoma protuberans and CD34+ by immunohistochemistry.

4. Superficial, CD34+ tumor with typical histomorphology of dermatofibrosarcoma protuberans except that good honeycombing of fat is not seen due to superficial sampling.

5. Superficial, CD34+ tumor with nontypical histomorphology for dermatofibrosarcoma protuberans. (SD5)

6. Superficial, CD34+ tumor with scant tumor sampling as to limit cytologic and/or architectural evaluation.

7. High grade spindle cell tumor ("fibrosarcomatous transformation") and no areas of typical histomorphology of dermatofibrosarcoma protuberans.

8. Metastatic tumor with histomorphology similar to previously diagnosed primary dermatofibrosarcoma protuberans.

9. Metastatic tumor with histomorphology distinct from previously diagnosed primary dermatofibrosarcoma protuberans.

10. Patient with locally recurrent dermatofibrosarcoma protuberans in which testing for translocation by another established molecular technique (RT-PCR, FISH and cytogenetics) was previously positive.

11. Patient with metastatic dermatofibrosarcoma protuberans in which testing for translocation by another established molecular technique (RT-PCR, FISH and cytogenetics) was previously positive in the primary tumor.

12. Patients for which tyrosine kinase therapy is being considered in the treatment plan.

13. Patient with tissue that has been decalcified or processed with fixative other than $10 \%$ formalin.

14. Patient with a pathologic diagnosis of dermatofibrosarcoma protuberans by hematoxylin and eosin with CD34+ immunohistochemistry but where the treating physician is requesting molecular studies (RT-PCR, FISH and cytogenetics) to be performed to further confirm the diagnosis.

leg type (PCLBCL-LT) is considered in the diagnosis. The latter may be related to the lack of clarity among some panel raters for this scenario and the scarcity of literature pertaining to the use of clonality assays for more aggressive and rarer lymphomas.

\section{2 | Melanocytic group}

\subsection{1 | Fluorescence in situ hybridization and comparative genomic hybridization}

Regarding melanocytic lesions, ratings indicate that in most scenarios where the diagnosis of melanoma is in question it is reasonable to use FISH or $\mathrm{CGH}$ as an ancillary test. In general, the results of expert panel ratings for FISH and $\mathrm{CGH}$ were similar. Results were also 
TABLE 7 Soft tissue clinical scenarios and definitions for clear cell sarcoma

\section{Definitions:}

- Melanocytic markers: S100, Melan-A/MART-1, HMB45, MiTF and SOX10

- Typical histologic features of clear cell sarcoma: relatively uniform (nonpleomorphic) nuclei, large central nucleoli, nested appearance divided by fibrous septations, scattered osteoclast-like giant cells, little or no conspicuous melanin and no epidermal component

\section{Clinical scenarios:}

1. Patient less than 50 years of age with acral tumor with typical histologic features of clear cell sarcoma, expressing melanocytic markers and involving deep dermis, subcutis or aponeurosis. No past history of melanoma.

2. Patient less than 50 years of age with acral tumor WITHOUT typical histologic features of clear cell sarcoma, expressing melanocytic markers and involving deep dermis, subcutis or aponeurosis. No past history of melanoma.

3. Patient greater than or equal to 50 years of age with acral tumor with typical histologic features of clear cell sarcoma, expressing melanocytic markers and involving deep dermis, subcutis or aponeurosis. No past history of melanoma.

4. Patient greater than or equal 50 years of age with acral tumor WITHOUT typical histologic features of clear cell sarcoma, expressing melanocytic markers and involving deep dermis, subcutis or aponeurosis. No past history of melanoma.

5. Patient less than 50 years of age with NON-acral site tumor expressing melanocytic markers, WITHOUT typical histologic features of clear cell sarcoma and involving deep dermis, subcutis or aponeurosis. No past history of melanoma but with what appears to be a cutaneous metastasis of melanoma from an unknown primary.

6. Patient greater than or equal to 50 years of age with NON-acral site tumor expressing melanocytic markers, WITHOUT typical histologic features of clear cell sarcoma and involving deep dermis, subcutis or aponeurosis. No past history of melanoma but with what appears to be a cutaneous metastasis of melanoma from an unknown primary.

7. Patient with dermal-based tumor expressing melanocytic markers and demonstrating typical histological features of clear cell sarcoma. Patient has past history of invasive melanoma at another anatomic site.

8. Patient with an acral tumor in the dermis/subcutis that not only has typical histologic features of clear cell sarcoma and expresses melanocytic markers, but also has an overlying intraepidermal in situ component.

9. Patient with a non-acral tumor in the dermis/subcutis that not only has typical histologic features of clear cell sarcoma and expresses melanocytic markers but also has an overlying intraepidermal in situ component.

10. Patient with metastatic tumor with histomorphology similar to previously diagnosed primary clear cell sarcoma.

11. Patient with metastatic tumor with histomorphology distinct from previously diagnosed primary clear cell sarcoma.

12. Patient with recurrent or metastatic clear cell sarcoma in which testing for translocation by another established technique (RT$\mathrm{PCR}, \mathrm{FISH}$ and cytogenetics) was previously positive.

13. Patient with primary or metastatic tumor expressing melanocytic markers in which BRAF or NRAS mutation has been detected.

14. Patient with tissue that has been decalcified or processed with fixative other than $10 \%$ formalin.

similar across age groups (adult vs pediatric). In most scenarios, except for those where the pathology is definitive for melanoma or melanocytic nevus, expert rating found that it is "usually appropriate" to perform FISH or CGH on melanocytic lesions when the diagnosis is in question. In those cases where the pathology is definitive for
TABLE 8 Lymphoproliferative T-cell Clonality Beta and Gamma appropriate use scores

\begin{tabular}{|c|c|c|}
\hline Clinical scenario* & Beta ratings & $\begin{array}{l}\text { Gamma } \\
\text { ratings }\end{array}$ \\
\hline $\begin{array}{l}\geq 1 \text { scaly patches/plaques concerning for } \\
\text { MF; histology and IHC "concerning," } \\
\text { "suspicious" or "suggestive of" MF }\end{array}$ & UA (8.0) & UA (7.9) \\
\hline $\begin{array}{l}\text { Erythroderma; clinical r/o MF/CTCL/ } \\
\text { Sézary dz; histology "not diagnostic" } \\
\text { for MF }\end{array}$ & NC (5.6) & NC (5.8) \\
\hline $\begin{array}{l}\text { Dermatitis; clinical r/o MF/CTCL; } \\
\text { histology "not diagnostic" for MF }\end{array}$ & RA (2.8) & RA (2.8) \\
\hline $\begin{array}{l}\text { Inflam/react/papular/papulonecrotic } \\
\text { solitary/regional/generalized; clinical } \\
\text { r/o LyP, PL, MF, CTCL; histology } \\
\text { typical for LyP or PL }\end{array}$ & RA (2.1) & $\mathrm{RA}(2.1)$ \\
\hline $\begin{array}{l}\text { Histology of a T-cell infiltrate "not } \\
\text { diagnostic for MF" in pt w/ Hx MF } \\
\text { and known clone (comparison of past } \\
\text { and present clone) }\end{array}$ & UA (7.1) & UA (7.1) \\
\hline $\begin{array}{l}\text { T-cell infiltrate in pt w/ Hx systemic T- } \\
\text { cell lymphoma }\end{array}$ & UAU (6.8) & UAU (6.9) \\
\hline $\begin{array}{l}\text { Histology of a folliculotropic T-cell } \\
\text { infiltrate }\end{array}$ & UA (7.1) & UA (7.2) \\
\hline $\begin{array}{l}\text { Pigmented purpuric patches solitary/ } \\
\text { regional/generalized; clinical r/o } \\
\text { MF/CTCL; histology "not diagnostic" } \\
\text { for MF }\end{array}$ & $\begin{array}{l}\text { RA }(2.7) \\
2 / 16 \\
\text { OUT }\end{array}$ & $\begin{array}{l}\text { RA (2.6) } \\
2 / 16 \text { OUT }\end{array}$ \\
\hline $\begin{array}{l}\text { Clinical reactive entities; histology and } \\
\text { IHC "concerning," "suspicious" or } \\
\text { "suggestive of" MF }\end{array}$ & $U(6.0)$ & $U(3.6)$ \\
\hline $\begin{array}{l}\text { New/evolving lesion in pt w/ Hx of MF; } \\
\text { clinical r/o MF; histology and IHC } \\
\text { "consistent with" MF }\end{array}$ & NC (3.4) & NC (3.1) \\
\hline $\begin{array}{l}\text { Nodules in patient w/ Hx of MF; } \\
\text { histology "concerning", "suspicious" or } \\
\text { "suggestive of" MF w/ CD30+ large } \\
\text { cell transformation }\end{array}$ & RA (2.8) & RA (2.8) \\
\hline $\begin{array}{l}\text { Nodules in patient w/ Hx of MF; } \\
\text { histology "concerning", "suspicious" or } \\
\text { "suggestive of" MF w/ out CD30+ } \\
\text { large cell transformation }\end{array}$ & $\mathrm{RA}(2.7)$ & $\mathrm{RA}(2.7)$ \\
\hline
\end{tabular}

*Refer to Table 1 for complete wording of the clinical scenarios and associated definitions.

Abbreviations: CTCL, cutaneous T-cell lymphoma; dz, disease; Hx, history; IHC, immunophenotype; inflam, inflammatory; LyP, lymphomatoid papulosis; MF, mycosis fungoides; PL, pityriasis lichenoides; pt, patient; r/o, rule out; react, reactive; $\mathrm{w} /$, with. Usually appropriate indications (UA; mean' scores of $\geq 7.0$ ) are colored dark green; Usually appropriate to uncertain ("majority usually appropriate") indications (UAU; mean' scores between 6.1 and 6.9 and SD <2.0) are colored light green; Rarely appropriate indications (RA; mean' scores of $\leq 3.0$ ) are colored dark red; Rarely appropriate to uncertain (majority rarely appropriate) indications (RAU; mean' scores between 3.1 and 3.9 and SD <2.0) are colored light red; Uncertain appropriateness indications ( $U$; mean' scores of $\geq 4.0$ and $\leq 6.0$ with a SD $<2.0$ ) are colored blue; No consensus (NC; mean' scores between 3.1 and 6.9 that had a SD $[S D] \geq 2.0$ ) are colored white.

either a melanoma or melanocytic nevus, testing with FISH and CGH is "rarely appropriate." This was not surprising as histology is considered the "gold standard" in the diagnosis of melanocytic lesions. Of note, inclusion of these clinical scenarios may be considered a proof of concept that the rounds of ratings yielded meaningful results. Interestingly, the results also indicate that currently CGH is the only test ranked "usually appropriate" when it comes to distinguishing benign blue nevi from more worrisome dermal melanocytoses. The 
TABLE 9 Lymphoproliferative B-cell receptor (IgH) gene rearrangement by PCR appropriate use scores

\begin{tabular}{|c|c|}
\hline Clinical scenario* & IgH ratings \\
\hline $\begin{array}{l}\geq 1 \text { erythematous concerning nodules; clinical r/o B-cell } \\
\text { lymphoma; histology and IHC "concerning for," } \\
\text { "suspicious of," or "suggestive of" PCMZL }\end{array}$ & UA (7.8) \\
\hline $\begin{array}{l}\geq 1 \text { erythematous concerning nodules; clinical r/o B-cell } \\
\text { lymphoma; histology and IHC "concerning for," } \\
\text { "suspicious of," or "suggestive of" FCL }\end{array}$ & UA (8.1) \\
\hline $\begin{array}{l}\geq 1 \text { nodules; clinical CLH; histology and IHC "concerning } \\
\text { for," "suspicious of," or "suggestive of" PCMZL }\end{array}$ & UA (8.2) \\
\hline $\begin{array}{l}\geq 1 \text { nodules; clinical CLH; histology and IHC "concerning } \\
\text { for," "suspicious of," or "suggestive of" FCL }\end{array}$ & UA (8.2) \\
\hline $\begin{array}{l}\geq 1 \text { erythematous concerning nodules; clinical r/o B-cell } \\
\text { lymphoma (PCMZL or FCL); histology and IHC "not } \\
\text { diagnostic" for cutaneous B-cell lymphoma }\end{array}$ & RA (2.7) \\
\hline $\begin{array}{l}1 \text { lesion; clinical s/o non-neoplastic process; B-cell } \\
\text { predominant infiltrate }\end{array}$ & UAU (6.6) \\
\hline $\begin{array}{l}\text { Dermatitis; clinical s/o non-neoplastic process; B-cell } \\
\text { predominant infiltrate }\end{array}$ & UAU (6.9) \\
\hline $\begin{array}{l}\text { Unknown Hx; histology and IHC "consistent with" } \\
\text { PCMZL or FCL }\end{array}$ & NC (6.6) \\
\hline $\begin{array}{l}\text { New/evolving lesion in pt w/ prior ddx of B-cell } \\
\text { lymphoma (PCMZL or FCL); clinical r/o B-cell } \\
\text { lymphoma; histology and IHC "consistent with" } \\
\text { PCMZL or FCL }\end{array}$ & RA (2.6) \\
\hline $\begin{array}{l}\geq 1 \text { nodules; clinical concerning for aggressive B-cell } \\
\text { lymphoma r/o B-cell lymphoma, leg type; histology } \\
\text { and IHC "concerning for," "suspicious of" or } \\
\text { "suggestive of" PCLBCL, LT }\end{array}$ & UA (7.7) \\
\hline $\begin{array}{l}\text { Cutaneous B-cell infiltrate not diagnostic for B-cell } \\
\text { lymphoma but in a patient } \mathrm{w} / \mathrm{Hx} \text { of B-cell lymphoma } \\
\text { known clone (comparison of past and present clones) }\end{array}$ & UA (7.9) \\
\hline $\begin{array}{l}\text { Cutaneous B-cell infiltrate in a patient } \mathrm{w} / \mathrm{Hx} \text { of any } \\
\text { systemic B-cell lymphoma }\end{array}$ & UAU (6.8) \\
\hline $\begin{array}{l}\text { Other more aggressive cutaneous B-cell lymphoma other } \\
\text { than PCLBCL, LT (eg, IVL or cutaneous plasmablastic } \\
\text { lymphoma) }\end{array}$ & NC (5.2) \\
\hline
\end{tabular}

*Refer to Table 2 for complete wording of the clinical scenarios and associated definitions.

Abbreviations: FCL, follicle center lymphoma; Hx, history of; IHC, immunophenotype; IVL, intravascular lymphoma; PCLBCL, LT, primary cutaneous large B-cell lymphoma, leg type; PCMZL, primary cutaneous marginal zone lymphoma; r/o, rule out; s/o, suggestive of; w/, with. Usually appropriate indications (UA; mean' scores of $\geq 7.0$ ) are colored dark green; Usually appropriate to uncertain ("majority usually appropriate") indications (UAU; mean' scores between 6.1 and 6.9 and SD <2.0) are colored light green; Rarely appropriate indications (RA; mean' scores of $\leq 3.0$ ) are colored dark red; Rarely appropriate to uncertain (majority rarely appropriate) indications (RAU; mean' scores between 3.1 and 3.9 and SD <2.0) are colored light red; Uncertain appropriateness indications (U; mean' scores of $\geq 4.0$ and $\leq 6.0$ with a SD $<2.0$ ) are colored blue; No consensus (NC; mean' scores between 3.1 and 6.9 that had a SD $\geq 2.0$ ) are colored white.

consensus rating for FISH in the same clinical scenario was of uncertain appropriateness. Pouryazdanparast et al described the utility in epithelioid blue nevi and cutaneous melanoma metastases simulating blue nevi ${ }^{15}$ and Gammon et al explored FISH in distinguishing cellular blue nevi from blue nevus-like melanoma showing $100 \%$ sensitivity and specificity. ${ }^{16}$ While these studies utilized a FISH probe set different from the one defined by the group in this analysis, there was overlap of at least of 2 of the probes used-the RREB1 and $6 \mathrm{p} 25$ probes. There was "no consensus" on the value of FISH for situations where the pathology is suggestive or suspicious for melanoma where the differential diagnosis is between sclerosing desmoplastic nevus and desmoplastic melanoma, in partially sampled lesions. However, in this specific scenario, CGH was rated "usually appropriate." This may relate to Gerami et al in 2011, which showed a low sensitivity but high specificity in this subset with FISH. ${ }^{17}$

The "OUT" rating was used once in 3 clinical scenarios by the panel raters when rating $\mathrm{FISH}$ and $\mathrm{CGH}$, with $94 \%$ of panel raters participating. Scenarios rated for FISH and $\mathrm{CGH}$ independently showed the same number of "OUT" ratings and when they were considered in pediatric vs adult patients the use of "OUT" was similar.

\subsubsection{Quantitative reverse transcription polymerase chain reaction}

Consensus ratings in most of the clinical scenarios using qRT-PCR were of "appropriateness uncertain" with the exception being those cases where a diagnosis can be made on histologic grounds. While validation studies and studies exploring unequivocal cases had been published when the AUC process began, ${ }^{18,19}$ only one study was available exploring the test in ambiguous lesions ${ }^{20}$ at the time of rating. In addition, the possibility of limited clinical experience with the test may have played a role in the rating result. Since the completion of the AUC process, additional studies have been reported in the literature, including one dealing with diagnostically challenging cases $^{21}$ and another that correlates with clinical outcome. ${ }^{22}$ Thus, recommendations for the appropriateness of qRT-PCR in the studied clinical scenarios are expected to change as the AUC are subsequently and expectedly updated.

\section{3 | Other groups}

\subsubsection{Human papillomavirus, in situ hybridization and immunohistochemistry}

Use of HPV, ISH and IHC shows wide variability and these tests are currently frequently performed and often at the request of clinicians. Although there are many commercially available type-specific probes and "cocktails" for the detection of HPV by ISH, type-specific probes for HPV 6, 11, 16, 18, 31 and 33 are the most commonly utilized by dermatopathologists. The availability of commercially available antibodies targeting HPV is much more limited, with only 2 currently available. ${ }^{11}$

While most of the literature for detection of HPV centers on use of ISH in condylomas or lesions histologically concerning for condylomas in adults, consensus ratings found testing by ISH to be "rarely appropriate" to "majority rarely appropriate" for many scenarios ranked. Only in pediatric cases where pathology is suggestive of condyloma, did experts feel testing by ISH was "usually appropriate." Literature on this topic suggests that sensitivities for detection of HPV by ISH in the pediatric population ranges from $60 \%$ to $100 \%,{ }^{23-26}$ which may be the reason for the recommendation. However, there was "no consensus" in a similar scenario of a pediatric patient, but with histology definitive for condyloma. This rating may be because HPV 2, which is not typically detected by ISH, is the most common subtype of HPV found in this age group. ${ }^{27}$

Most scenarios were ranked as "rarely appropriate" for the use of IHC in the detection of HPV. These ratings probably reflect the 
TABLE 10 Melanocytic appropriate use scores

\begin{tabular}{|c|c|c|c|c|}
\hline Clinical scenario* & $\begin{array}{l}\text { Patient } \\
\text { type }\end{array}$ & FISH ratings & CGH ratings & $\begin{array}{l}\text { qRT-PCR } \\
\text { ratings }\end{array}$ \\
\hline \multirow[t]{2}{*}{ Pathology definitive for MM } & Adult/ & RA (1.1/1.5) & RA (1.2 /1.4) & RA $(1.2 / 1.2)$ \\
\hline & Pediatric & $\begin{array}{l}1 / 16 \text { OUT-pediatric } \\
\text { patients }\end{array}$ & $\begin{array}{l}\text { 1/16 OUT-pediatric } \\
\text { patients }\end{array}$ & \\
\hline \multirow{2}{*}{$\begin{array}{l}\text { Pathology suggestive/suspicious for MM (DDx nevoid } \\
\text { MM vs benign melanocytic nevus) }\end{array}$} & Adult/ & UA $(7.4 / 7.8)$ & UA (7.7/7.9) & $U(4.9 / 4.9)$ \\
\hline & Pediatric & & & \\
\hline \multirow{2}{*}{$\begin{array}{l}\text { Pathology suggestive/suspicious for MM (DDx MM } \\
\text { arising } \mathrm{w} / \text { in nevus/dysplastic nevus) }\end{array}$} & Adult/ & UA $(7.0 / 7.5)$ & UA $(7.7 / 7.6)$ & $U(4.7 / 4.6)$ \\
\hline & Pediatric & & & \\
\hline \multirow{2}{*}{$\begin{array}{l}\text { Pathology suggestive/suspicious for MM (DDx atypical } \\
\text { blue nevus vs benign blue nevus) }\end{array}$} & Adult/ & $\mathrm{U}(4.4 / 4.3)$ & UA (7.0) & U (4.4/4.4) \\
\hline & Pediatric & & NC (6.8) & \\
\hline $\begin{array}{l}\text { Pathology suggestive/suspicious for MM (DDx malignant } \\
\text { blue nevus vs benign blue nevus) }\end{array}$ & Pediatric & & & \\
\hline \multirow{2}{*}{$\begin{array}{l}\text { Pathology suggestive/suspicious for MM (DDx cong } \\
\text { nevus with prolif nodule vs MM) }\end{array}$} & Adult/ & UA $(7.6 / 7.7)$ & UA $(7.9 / 7.9)$ & U (4.8/4.8) \\
\hline & Pediatric & & & \\
\hline \multirow{2}{*}{$\begin{array}{l}\text { Pathology suggestive/suspicious for MM (DDx atypical } \\
\text { Spitz vs Spitzoid MM) }\end{array}$} & Adult/ & UA (7.6/7.1) & UA $(7.7 / 7.9)$ & $U(4.9 / 4.8)$ \\
\hline & Pediatric & & & \\
\hline \multirow{2}{*}{$\begin{array}{l}\text { Pathology suggestive/suspicious for MM; incompletely } \\
\text { sampled (DDx unclassified Spitz vs Spitzoid MM) }\end{array}$} & Adult/ & UA (7.6/7.1) & UA $(7.2 / 7.6)$ & $\cup(4.9 / 4.7)$ \\
\hline & Pediatric & & & \\
\hline \multirow{2}{*}{$\begin{array}{l}\text { Pathology suggestive/suspicious for MM; incompletely } \\
\text { sampled (DDx sclerosing desmoplastic nevus vs } \\
\text { desmoplastic MM) }\end{array}$} & Adult/ & NC (6.4/6.2) & UA (7.0/7.3) & U (4.4/4.4) \\
\hline & Pediatric & & & \\
\hline \multirow[t]{2}{*}{ Partial bx; light microscopy not definitive } & Adult/ & UA $(7.5 / 7.3)$ & UA $(7.2 / / 7.5)$ & $U(4.9 / 4.6)$ \\
\hline & Pediatric & $\begin{array}{l}\text { 1/16 OUT-adult patient; } \\
1 / 16 \text { OUT-pediatric } \\
\text { patient }\end{array}$ & $\begin{array}{l}1 / 16 \text { OUT-adult patient; } \\
1 / 16 \text { OUT-pediatric patient }\end{array}$ & \\
\hline \multirow[t]{2}{*}{ DDx nevus vs met; light microscopy not definitive } & Adult/ & UA $(7.5 / 7.6)$ & UA $(7.9 / 7.9)$ & $\mathrm{U}(4.6 / 4.3)$ \\
\hline & Pediatric & & & \\
\hline \multirow{2}{*}{$\begin{array}{l}\text { DDx nevus vs met; partial bx; light microscopy not } \\
\text { definitive }\end{array}$} & Adult/ & UA $(7.5 / 7.4)$ & UA $(7.3 / 7.5)$ & $\mathrm{U}(4.4 / 4.2)$ \\
\hline & Pediatric & $\begin{array}{l}1 / 16 \text { OUT-adult patient; } \\
1 / 16 \text { OUT-pediatric } \\
\text { patient }\end{array}$ & $\begin{array}{l}\text { 1/16 OUT-adult patient; } \\
1 / 16 \text { OUT-pediatric patient }\end{array}$ & \\
\hline
\end{tabular}

*Refer to Table 3 for complete wording of the clinical scenarios and associated definitions.

Abbreviations: bx, biopsy; CGH, comparative genomic hybridization; cut, cutaneous; cong, congenital; DDx, differential diagnosis; FISH, florescence in situ hybridization; MM, melanoma; mel, melanocytic; met, metastasis; prolif, proliferative; qRT-PCR, quantitative reverse transcription polymerase chain reaction; SS, special sites; vs, versus; w/ in, within. Usually appropriate indications (UA; mean' scores of $\geq 7.0$ ) are colored dark green; Usually appropriate to uncertain ("majority usually appropriate") indications (UAU; mean' scores between 6.1 and 6.9 and SD <2.0) are colored light green; Rarely appropriate indications (RA; mean' scores of $\leq 3.0$ ) are colored dark red; Rarely appropriate to uncertain (majority rarely appropriate) indications (RAU; mean' scores between 3.1 and 3.9 and SD <2.0) are colored light red; Uncertain appropriateness indications ( $\mathrm{U}$; mean' scores of $\geq 4.0$ and $\leq 6.0$ with a SD $<2.0$ ) are colored blue; No consensus (NC; mean' scores between 3.1 and 6.9 that had a SD $\geq 2.0$ ) are colored white.

presence of only 2 articles exploring the use of IHC for detection of HPV.

A significant number of panel raters utilized the "OUT" rating in scenarios dealing with the use of ISH and IHC for the detection of HPV. The scenarios with a significant number of "OUT" ratings were those where the pathology is "suggestive of" a condyloma in an adult, in situations when the pathology is definitive or "suggestive of" a condyloma in the pediatric population, and in cases where the pathology is "consistent with" a seborrheic keratosis of the genital skin, perineum, lower abdomen or inner thighs. This likely reflects the psychosocial implications surrounding a diagnosis of HPV, especially in the genital area and in children, emphasizing the importance of direct communication between dermatopathologist and clinician before performing these tests. 
TABLE 11 HPV appropriate use scores

\begin{tabular}{|c|c|c|}
\hline Clinical scenario* & ISH ratings & IHC ratings \\
\hline Adult; definitive for condyloma & $\begin{array}{c}\text { RA (1.6) } \\
1 / 16 \\
\text { OUT }\end{array}$ & $\begin{array}{l}\text { RA }(1.5) \\
1 / 16 \\
\text { OUT }\end{array}$ \\
\hline Adult suggestive of condyloma & $\begin{array}{l}\text { U (6.3) } \\
3 / 16 \\
\text { OUT }\end{array}$ & $\begin{array}{l}U(5.2) \\
2 / 16 \\
\text { OUT }\end{array}$ \\
\hline Pediatric; definitive for condyloma & $\begin{array}{l}\text { NC (6.0) } \\
4 / 16 \\
\text { OUT }\end{array}$ & $\begin{array}{l}\text { NC (4.1) } \\
3 / 16 \\
\text { OUT }\end{array}$ \\
\hline Pediatric; suggestive of condyloma & $\begin{array}{l}\text { UA (7.5) } \\
4 / 16 \\
\text { OUT }\end{array}$ & $\begin{array}{l}\text { NC (5.7) } \\
4 / 16 \\
\text { OUT }\end{array}$ \\
\hline $\begin{array}{l}\text { Age }<25 \text {; pathologic findings } \mathrm{c} / \mathrm{w} \\
\text { seborrheic keratosis of genital skin, } \\
\text { perineum, lower abdomen, or inner } \\
\text { thighs }\end{array}$ & $\begin{array}{l}\text { UAU }(6.7) \\
4 / 16 \\
\text { OUT }\end{array}$ & $\begin{array}{l}\mathrm{U}(3.6) \\
3 / 16 \\
\text { OUT }\end{array}$ \\
\hline $\begin{array}{l}\text { SCCIS/ undifferentiated intraepithelial } \\
\text { dysplasia of the genital skin }\end{array}$ & $\begin{array}{l}\mathrm{U}(3.7) \\
1 / 16 \\
\text { OUT }\end{array}$ & $\begin{array}{c}\text { RA }(2.8) \\
1 / 16 \\
\text { OUT }\end{array}$ \\
\hline SCC in the genital area & NC (3.9) & RA (2.8) \\
\hline $\begin{array}{l}\mathrm{Hx} \text { HPV induced lesion and a SCC in the } \\
\text { genital area }\end{array}$ & $\operatorname{RAU}(3.6)$ & RA (2.8) \\
\hline $\begin{array}{l}\text { SCC in the genital area and } \mathrm{Hx} \text { chronic } \\
\text { dermatoses (ie, LSEA, LP) }\end{array}$ & RAU (3.2) & RA (2.7) \\
\hline $\begin{array}{l}\text { Clinical impression and pathology c/w } \\
\text { verrucous carcinoma }\end{array}$ & RAU (3.3) & RA (2.3) \\
\hline Subungual wart & $\begin{array}{l}\text { RA (2.0) } \\
1 / 16 \text { OUT }\end{array}$ & $\begin{array}{l}\text { RA (2.1) } \\
\quad 1 / 16 \text { OUT }\end{array}$ \\
\hline $\begin{array}{l}\text { Nail bed, periungual or nail matrix SCCIS } \\
\text { or SCC }\end{array}$ & RA (2.6) & RA (2.2) \\
\hline $\begin{array}{l}\text { SCCIS or SCC w/ verrucous features on } \\
\text { digits }\end{array}$ & RA (2.9) & RA (2.2) \\
\hline $\begin{array}{l}\text { Immunosuppressed patients with SCCIS } \\
\text { or SCC with verrucous features }\end{array}$ & RAU (3.3) & RA (2.6) \\
\hline
\end{tabular}

${ }^{*}$ Refer to Table 4 for complete wording of the clinical scenarios and associated definitions.

Abbreviations: c/w, consistent with; IHC, immunohistochemistry; ISH, in situ hybridization; LP, lichen planus; LSEA, Lichen sclerosus et atrophicus; SCCIS, squamous cell carcinoma in situ; SCC, squamous cell carcinoma. Usually appropriate indications (UA; mean' scores of $\geq 7.0$ ) are colored dark green; Usually appropriate to uncertain ("majority usually appropriate") indications (UAU; mean' scores between 6.1 and 6.9 and SD <2.0) are colored light green; Rarely appropriate indications (RA; mean' scores of $\leq 3.0$ ) are colored dark red; Rarely appropriate to uncertain (majority rarely appropriate) indications (RAU; mean' scores between 3.1 and 3.9 and SD $<2.0$ ) are colored light red; Uncertain appropriateness indications $(\mathrm{U}$; mean' scores of $\geq 4.0$ and $\leq 6.0$ with a SD $<2.0$ ) are colored blue; No consensus (NC; mean' scores between 3.1 and 6.9 that had a SD $\geq 2.0$ ) are colored white.

\subsection{2 | Muir-Torre syndrome mismatch repair immunohistochemistry}

MTS is a clinical variant of Lynch syndrome defined by the synchronous or metachronous occurrence of at least one sebaceous neoplasm or keratoacanthoma and at least one Lynch syndrome-related internal cancer in a patient irrespective of family history or age at onset. ${ }^{6,28} \mathrm{~A}$ universal screening for Lynch syndrome has been recommended by major task forces and groups for all new colorectal cancers in patients who are 70 years old or under ${ }^{29}$; however, with respect to MTSassociated skin neoplasms, no formal screening guidelines have been established. Although sensitivity as high as $81 \%$ has been reported in the literature for MMR analysis by IHC in sebaceous neoplasms,
TABLE 12 Muir-Torre syndrome appropriate use scores

\begin{tabular}{|c|c|c|}
\hline Clinical scenario* & $\begin{array}{l}4 \mathrm{AB} \text { panel } \\
\text { ratings }\end{array}$ & $\begin{array}{l}2 \mathrm{AB} \text { panel } \\
\text { ratings }\end{array}$ \\
\hline Age > 60; periocular sebca & NC (3.5) & RA (3.0) \\
\hline Age $>60 ; 1$ seb tumor $\mathrm{H} \& N$ & $\begin{array}{l}\text { NC (5.1) } \\
1 / 16 \text { OUT }\end{array}$ & $\begin{array}{l}\text { U (4.9) } \\
1 / 16 \text { OUT }\end{array}$ \\
\hline Age $>60 ; 1$ seb tumor non-H\&N & $\begin{array}{l}\text { NC (6.7) } \\
1 / 16 \text { OUT }\end{array}$ & $\begin{array}{l}\text { UAU (6.9) } \\
1 / 16 \text { OUT }\end{array}$ \\
\hline Age $>60$; multiple seb tumors & UA (7.2) & UA (7.2) \\
\hline Age > 60; BCC w/ seb diff & $\mathrm{U}(5.0)$ & $\mathrm{U}(4.6)$ \\
\hline Age > 60; KA w/ seb diff & UA (7.1) & UAU (6.6) \\
\hline Age > 60; cystic seb neoplasm & UA (7.3) & UAU (6.9) \\
\hline $\begin{array}{l}\text { Age }>60 \text {; MTS assoc. neoplasm \&/ } \\
\text { or visceral malignancy }\end{array}$ & $\begin{array}{l}\text { UA (7.3) } \\
1 / 16 \text { OUT }\end{array}$ & UAU (6.9) \\
\hline
\end{tabular}

*Refer to Table 5 for complete wording of the clinical scenarios and associated definitions.

Abbreviations: assoc, associated; H\&N, site head and neck; MTS, MuirTorre syndrome; sebca, sebaceous carcinoma; seb, sebaceous; seb diff, sebaceous differentiation. Usually appropriate indications (UA; mean' scores of $\geq 7.0$ ) are colored dark green; Usually appropriate to uncertain ("majority usually appropriate") indications (UAU; mean' scores between 6.1 and 6.9 and SD <2.0) are colored light green; Rarely appropriate indications (RA; mean' scores of $\leq 3.0$ ) are colored dark red; Rarely appropriate to uncertain (majority rarely appropriate) indications (RAU; mean' scores between 3.1 and 3.9 and SD <2.0) are colored light red; Uncertain appropriateness indications ( $\mathrm{U}$; mean' scores of $\geq 4.0$ and $\leq 6.0$ with a SD $<2.0$ ) are colored blue; No consensus (NC; mean' scores between 3.1 and 6.9 that had a SD $[S D] \geq 2.0$ ) are colored white.

studies where germline mutation analysis is also available point to a high false-positive rate presumably from nonheritable molecular events within the lesion. ${ }^{30-32}$

The average age of presentation of sebaceous neoplasms in MTS is 53 years old; however, the range is broad (21-88). Of note, these neoplasms can present before (22\%), concurrently with (6\%) or after (56\%) the internal malignancy. ${ }^{33}$ An age $>60$ years old was analyzed here, given the larger potential for misuse of MMR IHC. At a cellular level, MMR proteins bind as heterodimers, with MLH1 binding to its secondary partner PMS2 and MSH2 binding to MSH6. Mutations in MLH1 and MSH2 account for the vast majority of mutations in MTS, and isolated loss of secondary partners PMS2 and MSH6 is rare. With this in mind, and the preponderance of literature employing a panel of MLH1 and MSH2, this was chosen as the 2-antibody panel to be rated. However, a panel employing PMS2 and MSH6 may show greater promise, but needs validation that includes germline mutation analysis and a larger cohort of sebaceous neoplasms. ${ }^{34}$

The results for the 4- and 2-antibody panels rated were similar and mirror the weak to moderate support for the global use of MMR protein analysis by IHC in sebaceous neoplasms and neoplasms associated with MTS. Recent scientific evidence suggesting a tailored approach using clinical parameters is reflected by the ratings. Only those scenarios where multiple sebaceous neoplasms were encountered and scenarios where the patient had a history of an MTSassociated neoplasm and/or visceral malignancy was the test found to be "usually appropriate." Not surprisingly, other strong indicators of MTS, such as the presence of sebaceous differentiation within a keratoacanthoma and the presence of a cystic sebaceous neoplasm were also found to be "usually appropriate" following the rounds of expert rating. 
TABLE $13 \quad t(17 ; 22)$ in dermatofibrosarcoma protuberans appropriate use scores

\begin{tabular}{|c|c|}
\hline Clinical scenario* & $\begin{array}{l}t(17: 22) \\
\text { ratings }\end{array}$ \\
\hline Histology typical for DFSP; CD34+ & RA (1.4) \\
\hline Histology typical for DFSP; CD34 not uniformly reactive & NC (3.2) \\
\hline Histology not typical for DFSP; CD34+ & UA (7.2) \\
\hline $\begin{array}{l}\text { Histology typical for DFSP; CD34+; but SQ not } \\
\text { visualized }\end{array}$ & NC (4.7) \\
\hline $\begin{array}{l}\text { Histology not typical for DFSP; CD34+; SQ not } \\
\text { visualized }\end{array}$ & UAU (6.5) \\
\hline $\begin{array}{l}\text { Limited cytological and / or architectural histology } \\
\text { evaluation; CD34+ }\end{array}$ & $\begin{array}{l}\text { NC (6.0) } \\
\quad 7 / 16 \text { OUT }\end{array}$ \\
\hline $\begin{array}{l}\text { Fibrosarcoma-like (high grade) histology; no histology } \\
\text { typical for DFSP }\end{array}$ & UAU (6.9) \\
\hline Met lesion with histology similar to prior DFSP & $\begin{array}{l}\text { RA (2.9) } \\
1 / 16 \text { OUT }\end{array}$ \\
\hline Met lesion with histology different from prior DFSP & $U(6.5)$ \\
\hline $\begin{array}{l}\text { Locally recurrent DFSP; + translocation testing by other } \\
\text { molecular test }\end{array}$ & RA (1.6) \\
\hline $\begin{array}{l}\text { Met DFSP; + translocation testing by other molecular } \\
\text { test }\end{array}$ & RA (1.7) \\
\hline Tyrosine kinase therapy is being considered & $\begin{array}{l}\text { UA (7.2) } \\
1 / 16 \text { OUT }\end{array}$ \\
\hline $\begin{array}{l}\text { Tissue that has been decalcified or processed } w / \text { fixative } \\
\text { other than } 10 \% \text { formalin }\end{array}$ & UAU (6.6) \\
\hline $\begin{array}{l}\text { Histology typical for DFSP; CD34+; treating MD } \\
\text { requesting cytogenetics to confirm diagnosis }\end{array}$ & $\begin{array}{l}\text { UAU (6.3) } \\
3 / 16 \text { OUT }\end{array}$ \\
\hline
\end{tabular}

*Refer to Table 6 for complete wording of the clinical scenarios and associated definitions.

Abbreviations: DFSP, dermatofibrosarcoma protuberans; histology typical, monotonous spindled cells in a storiform pattern with "honeycombing" or entrapment of adnexal structures and/or adipocytes and extension into the subcutis; ; Met, metastatic; SQ, subcutis; w/, with. Usually appropriate indications (UA; mean' scores of $\geq 7.0$ ) are colored dark green; Usually appropriate to uncertain ("majority usually appropriate") indications (UAU; mean' scores between 6.1 and 6.9 and SD $<2.0$ ) are colored light green; Rarely appropriate indications (RA; mean' scores of $\leq 3.0$ ) are colored dark red; Rarely appropriate to uncertain (majority rarely appropriate) indications (RAU; mean' scores between 3.1 and 3.9 and SD <2.0) are colored light red; Uncertain appropriateness indications ( $U$; mean' scores of $\geq 4.0$ and $\leq 6.0$ with a SD <2.0) are colored blue; No consensus (NC; mean' scores between 3.1 and 6.9 that had an SD $\geq 2.0$ ) are colored white.

Interestingly, the "OUT" option was not used frequently in the rating of these clinical scenarios.

\section{4 | Soft tissue group}

\subsection{1 | $t(17 ; 22)$ FISH assay for DFSP}

Cytogenetically, DFSP is characterized by a balanced or unbalanced translocation, $\mathrm{t}(17 ; 22)(\mathrm{q} 22 ; \mathrm{q} 13)$ or a supernumerary ring chromosome, resulting in the fusion of exon 2 of PDGFB gene encoding the platelet-derived growth factor beta with various exons (from 6-47) of COL1A1 gene encoding the alpha chain type 1 collagen. Multiple modalities of FISH can be utilized to detect the translocation. These include: dual-fusion COL1A1/PDGFB FISH, PDGFB break-apart FISH or COL1A1 break-apart FISH. ${ }^{35-40}$ The overall sensitivity of the dualfusion FISH test in the literature is $94.3 \%$ (range $86 \%-100 \%$ ). This was similar for PDGFB break-apart FISH that has an overall sensitivity of 95\% (range 91\%-100\%). The sensitivity of the COL1A1 break-apart probe is probably in the same range; however, there is only one study
TABLE 14 EWSR1 FISH clear cell sarcoma appropriate use scores

\begin{tabular}{l} 
Clinical scenario* \\
\hline Age < 50; typical location; tumor w/ histology typical \\
for CCS, expressing melanocytic markers, involving \\
deep dermis, SQ or aponeurosis. No Hx of \\
melanoma
\end{tabular}

Age < 50; typical location; tumor w/ non-typical histology for CCS expressing melanocytic markers, involving deep dermis, SQ or aponeurosis. No $\mathrm{Hx}$ of melanoma

Age $\geq 50$; typical location; tumor w/ histology typical for CCS, expressing melanocytic markers, involving deep dermis, SQ or aponeurosis. No Hx of melanoma

Age $\geq 50$; typical location; tumor w/ non-typical histology for CCS expressing melanocytic markers, involving deep dermis, SQ or aponeurosis. No Hx of melanoma

Age < 50; non-typical location; tumor expressing melanocytic markers; w/ non-typical histology for $\mathrm{CCS}$, involving deep dermis, SQ or aponeurosis. No $\mathrm{Hx}$ of melanoma but w/ what appears to be cut met of MM from unknown primary

Age $\geq 50$; non-typical location; tumor expressing melanocytic markers; w/ non-typical histology for CCS, involving deep dermis, SQ or aponeurosis. No $\mathrm{Hx}$ of melanoma but w/ what appears to be cut met of MM from unknown primary

Dermal tumor expressing melanocytic markers and demonstrating typical histology of CCS. Pt has $\mathrm{Hx}$ invasive $\mathrm{MM}$ at another site.

Typical location; tumor in dermis/subcutis; histology typical for CCS, expressing melanocytic markers, but also has an intraepidermal in situ component

Non-typical location; tumor in dermis/subcutis; histology typical for CCS expressing melanocytic markers, but also has an intraepidermal in situ component

Met tumor w/ histology similar to previous CCS

Met tumor w/ histology different from previous CCS

Recurrent / met CCS w/ translocation testing by other method positive

Primary or met tumor expressing melanocytic markers; BRAF or NRAS mutation detected

Tissue that has been decalcified or processed $\mathrm{w} /$ fixative other than $10 \%$ formalin
EWSR1 FISH ratings

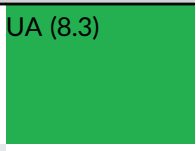

NC (6.3)

\section{un \\ UA (8.1)}

RAU (3.4)

\section{.}

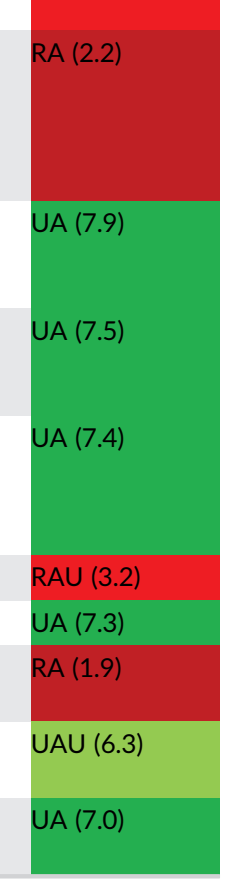

*Refer to Table 7 for complete wording of the clinical scenarios and associated definitions.

Abbreviations: CCS, clear cell sarcoma; $\mathrm{Hx}$, history; MM, malignant melanoma; Met, metastatic; SQ, subcutis; typical histology, tumor with a distinctly nested growth pattern that is divided by fibrous septations. Cells have a relatively uniform nucleus and large central nucleoli. Scattered osteoclast-like giant cells can be seen. There is little to no melanin appreciated; typical location, deep soft tissue of tendon, aponeuroses and fascial structures of the distal extremities; $w /$, with. Usually appropriate indications (UA; mean' scores of $\geq 7.0$ ) are colored dark green; Usually appropriate to uncertain ("majority usually appropriate") indications (UAU; mean' scores between 6.1 and 6.9 and SD <2.0) are colored light green; Rarely appropriate indications (RA; mean' scores of $\leq 3.0$ ) are colored dark red; Rarely appropriate to uncertain (majority rarely appropriate) indications (RAU; mean' scores between 3.1 and 3.9 and SD <2.0) are colored light red; Uncertain appropriateness indications ( $U$; mean' scores of $\geq 4.0$ and $\leq 6.0$ with a SD <2.0) are colored blue; No consensus (NC; mean' scores between 3.1 and 6.9 that had a SD $\geq 2.0$ ) are colored white.

that explicitly mentioned this probe being identified. ${ }^{41-44}$ Given the high sensitivity of FISH and the therapy potential if the translocation is detected, it is not surprising that the two scenarios where the test 
was found to be "usually appropriate" were situations when the histology of the tumor is not typical for DFSP and the tumor is CD34 reactive and situations where tyrosine kinase therapy is being considered.

The scenarios where the histology is not typical for DFSP and the tumor is CD34 reactive but the subcutis is not visualized were found to be "majority usually appropriate." Although this may suggest a bias from panel raters, that it may be more appropriate to discuss the case with the clinician and depending on clinical circumstances obtain a larger sample of the tumor to visualize deeper structures, this was not reflected using the "OUT" option. The frequent use of the "OUT" option ( $44 \%$ of panel raters) in the scenario where the sample provided for evaluation is limited both cytologically and architecturally probably underscores the importance of a discussion to ascertain the feasibility of obtaining more tissue prior to performing the test. The lack of consensus for this scenario is thus not surprising. Similarly, this may be the case when the tissue has not been processed in a standard manner because these tumors are usually large and accessible.

Interestingly, expert ratings found it "majority usually appropriate" to perform FISH in scenarios when only fibrosarcoma-like areas are visualized and when the clinician is requesting further confirmation of the diagnosis. Perhaps, the latter recommendation by panel raters considers that the clinician may be planning to use targeted therapy and is also reflected by three panel raters using the "OUT" option. Conversely, it is not surprising that results show testing to be "rarely appropriate" when the histology and IHC are supportive for a diagnosis of DFSP, a metastatic lesion is encountered with a similar histology to a prior DFSP, or in situations where testing for the translocation has been completed by another testing modality.

Although overall the "OUT" option was not used frequently for scenarios dealing with the use of FISH in the diagnosis of DFSP, there was one scenario in this group that had the highest number of "OUT" ratings of all 211 clinical scenarios. This was the scenario dealing with utility of the test in cases where the tissue available for evaluation is limited.

\subsection{2 | EWSR1 FISH assay for CCS}

CCS is a very rare aggressive soft tissue sarcoma showing neuroectodermal and melanocytic differentiation. ${ }^{45,46}$ It typically occurs in individuals $<50$ years of age and preferentially arises in the deep soft tissue of distal extremities. Although it shares some histologic overlap with melanoma, it is genetically and biologically distinct, resulting in prognostic differences. ${ }^{47,48}$ As there are significant consequences for misdiagnosis of CCS, it follows that expert rating found it "usually appropriate" to perform the dual-color break-apart EWSR1 FISH assay in cases where a histology typical of CSS is encountered, especially given the test's high specificity of $97.91 \%{ }^{49}$ This rating holds true regardless of age and if an intraepidermal component is found histologically. Additionally, testing is "usually appropriate" when a metastatic lesion is encountered in a patient with a previously diagnosed CCS, but the histology of the metastatic lesion appears distinct, and for situations where CCS is suspected, but the specimen was not fixed in standard fixative or decalcified. The majority of the panel raters would also do testing despite a BRAF or NRAS mutation having already been detected in either a primary or metastatic lesion. For clinical scenarios where a typical histology of CCS is lacking, older individuals and occurrence of CCS on nontypical locations testing for EWSR1 FISH was generally not recommended ("majority rarely appropriate"/"rarely appropriate"). Likewise, testing was "rarely appropriate" if the tumor has undergone testing to detect the translocation by another modality.

\section{5 | Overall conclusions}

This paper summarizes the first set of AUC in dermatopathology and represents the first AUC developed for pathology and the second AUC developed for dermatology using the RAND/UCLA methodology. The intent of these AUC is to provide guidance and clarification for use of a test in a particular clinical scenario. Although some of the scenarios specifically address adequacy of the sampled specimen, discretion and clinical judgment should be used regarding suitability of the test for a specific specimen. These guidelines may provide the foundation for studies exploring over and under use of tests/ancillary studies and serve as a model for further efforts in the field.

Evidence review was at the crux of expert judgment in ranking each scenario. Therefore, as new literature emerges, AUC developed here will need to be updated and may be revised. Importantly, scenarios that resulted in "no consensus" and consensus around "uncertain appropriateness" are areas where the body of evidence is controversial and/or underdeveloped. It is the hope that in addition to providing a guide for those using these tests/procedures for diagnosis of skin biopsy specimens, that the results of this process will also highlight the areas of needed and potential research.

The concept of appropriate and necessary care is essential for a healthcare system to be efficient and just. The development and implementation of AUC is necessary to address ambiguous approaches in utilizing ancillary studies with policy makers, healthcare organizations and the public.

\section{ACKNOWLEDGEMENTS}

The ASDP AUC Task Force would like to thank the following individuals for their expertise, input and support in developing the dermatopathology AUC: Drs. Klaus J. Busam, Garrett T. Desman, Dominick J. DiMaio, Jerad M. Gardner, Lawrence E. Gibson, Michael G. Hitchcock, Philip E. LeBoit, Julia S. Lehman, Vincent Liu, Timothy H. McCalmont, Jane L. Messina, Karl Napekoski, Rajiv M. Patel and Puja K. Puri.

\section{Disclaimer}

\section{ORCID}

Claudia I. Vidal (D) http://orcid.org/0000-0003-2672-4974

Jinah Kim (iD) http://orcid.org/0000-0002-5065-5916

Jason B. Lee (i) http://orcid.org/0000-0002-8154-4258

Brandon R. Litzner (D) http://orcid.org/0000-0001-9928-563X

Tricia A. Missall (D) http://orcid.org/0000-0001-9062-0606

Uma Sundram (D) http://orcid.org/0000-0002-0695-0045 
Maria Yadira Hurley (D) https://orcid.org/0000-0002-1162-7250

Patrick O. Emanuel (D) http://orcid.org/0000-0003-1068-6969

Maxwell A. Fung (D) http://orcid.org/0000-0003-1771-8257

Gregory A. Hosler (D) http://orcid.org/0000-0002-6281-0565

Alexander J. Lazar (D) http://orcid.org/0000-0002-6395-4499

\section{REFERENCES}

1. Brook RH, Vaiana ME. Using the knowledge base of health services research to redefine health care systems. J Gen Intern Med. 2015; 30(10):1547-1556.

2. Kuntz KM, Tsevat J, Weinstein MC, Goldman L. Expert panel vs decision-analysis recommendations for postdischarge coronary angiography after myocardial infarction. JAMA. 1999;282(23):2246-2251.

3. Fitch K, Bernstein S, Aguilar MS, et al. The RAND/UCLA Appropriateness Method User's Manual 2001. No. MR-1269-DG-XII/RE:126. Santa Monica, CA: RAND Corp.; 2001.

4. Berg G, Jaffe ES, Kempf W, et al. WHO/EORTC classification of cutaneous lymphomas. In: LeBoit PE, Burg G, Weedon D, Sarasin A, eds. WHO Classification of Skin Tumors. 4th ed. Lyon, France: IARC Press; 2006:165-228.

5. Martinez G, Copen CE, Abma JC. Teenagers in the United States: sexual activity, contraceptive use, and childbearing, 2006-2010 National Survey of family growth. National Center for Health Statistics. Vital Health Stat. 2011;23(31):1-35.

6. Calonje E, Brenn T, Lazar A, McKee PH, eds. McKee's Pathology of the Skin. 4th ed. China: Elsevier/Sanders; 2012.

7. Gill D, Dorevitch A, Marks R. The prevalence of seborrheic keratoses in people age 15 to 30 years: is the term senile keratosis redundant? Arch Dermatol. 2000;136(6):759-762.

8. John AM, Schwartz RA. Muir-Torre syndrome (MTS): an update and approach to diagnosis and management. J Am Acad Dermatol. 2016; 74(3):558-566.

9. Bhaijee F, Brown AS. Muir-Torre syndrome. Arch Pathol Lab Med. 2014;138(12):1685-1689.

10. Comfere NI, Sundram U, Hurley MY, Swick BL. Views of dermatopathologists about clonality assays in the diagnosis of cutaneous $\mathrm{T}$ cell and B cell lymphoproliferative disorders. J Cutan Pathol. 2018; 45(1):39-47.

11. Emanuel $\mathrm{PO}$, Andea $\mathrm{AA}$, Vidal $\mathrm{Cl}$, et al. Review of the medical literature and assessment of current utilization patterns regarding molecular testing for the diagnosis of cutaneous melanoma. J Cutan Pathol. [Submitted].

12. Litzner BR, Lee JB, Vidal $\mathrm{Cl}$. Review of the current medical literature and assessment of current utilization patterns regarding human papillomavirus in situ hybridization and immunohistochemistry in dermatopathology. J Cutan Pathol. 2017;44(11):938-943.

13. Lee JB, Litzner BR, Vidal $\mathrm{Cl}$. Review of the current medical literature and assessment of current utilization patterns regarding mismatch repair protein immunohistochemistry in cutaneous Muir-Torre syndrome-associated neoplasms. J Cutan Pathol. 2017;44(11):931-937.

14. Konstantinos L, Kozel JA, Hurley MY, Andea AA. Review of the medical literature and assessment of current utilization patterns regarding the use of two common fluorescence in situ hybridization assays for the diagnosis of dermatofibrosarcoma protuberans and clear cell sarcoma. J Cutan Pathol. [Submitted].

15. Pouryazdanparast P, Newman M, Mafee M, Haghighat Z, Guitart J, Gerami P. Distinguishing epithelioid blue nevus from blue nevus-like cutaneous melanoma metastasis using fluorescence in situ hybridization. Am J Surg Pathol. 2009;33(9):1396-1400.

16. Gammon B, Beilfuss B, Guitart J, Busam KJ, Gerami P. Fluorescence in situ hybridization for distinguishing cellular blue nevi from blue nevus-like melanoma. J Cutan Pathol. 2011;38(4):335-341.

17. Gerami P, Beilfuss B, Haghighat Z, Fang Y, Jhanwar S, Busam KJ. Fluorescence in situ hybridization as an ancillary method for the distinction of desmoplastic melanomas from sclerosing melanocytic nevi. J Cutan Pathol. 2011;38(4):329-334.
18. Clarke LE, Warf MB. Flake DD 2nd, et al.. Clinical validation of a gene expression signature that differentiates benign nevi from malignant melanoma. J Cutan Pathol. 2015;42(4):244-252.

19. Clarke LE, Flake DD 2nd, Busam K, et al. An independent validation of a gene expression signature to differentiate malignant melanoma from benign melanocytic nevi. Cancer 2017;123(4):617-628.

20. Minca EC, Al-Rohil RN, Wang M, et al. Comparison between melanoma gene expression score and fluorescence in situ hybridization for the classification of melanocytic lesions. Mod Pathol. 2016;29(8): 832-843.

21. Cockerell C, Tschen J, Billings SD, et al. The influence of a geneexpression signature on the treatment of diagnostically challenging melanocytic lesions. Per Med. 2017;14(2):123-130.

22. Ko JS, Matharoo-Ball B, Billings SD, et al. Diagnostic distinction of malignant melanoma and benign nevi by a gene expression signature and correlation to clinical outcomes. Cancer Epidemiol Biomarkers Prev. 2017;26(7):1107-1113.

23. Aguilera-Barrantes I, Magro C, Nuovo GJ. Verruca vulgaris of the vulva in children and adults: a nonvenereal type of vulvar wart. Am J Surg Pathol. 2007;31:529-535.

24. Nuovo GJ, Lastarria DA, Smith S, Lerner J, Comité SL, Eliezri YD. Human papillomavirus segregation patterns in genital and nongenital warts in prepubertal children and adults. Am J Clin Pathol. 1991;95: 467-474.

25. Yun K, Joblin L. Presence of human papillomavirus DNA in condylomata acuminata in children and adolescents. Pathology. 1993;25:1-3.

26. Padel AF, Venning VA, Evans MF, Quantrill AM, Fleming KA. Human papillomaviruses in anogenital warts in children: typing by in situ hybridisation. BMJ. 1990;300:1491-1494.

27. Handley J, Hanks E, Armstrong K, et al. Common association of HPV 2 with anogenital warts in prepubertal children. Pediatr Dermatol. 1997;14:339-343.

28. Schwartz RA, Torre DP. The Muir-Torre syndrome: a 25-year retrospect. J Am Acad Dermatol. 1995;33:90-104.

29. Giardiello FM, Allen JI, Axilbund JE, et al. Guidelines on genetic evaluation and management of lynch syndrome: a consensus statement by the US multi-society task force on colorectal cancer. Am J Gastroenterol. 2014;109:1159-1179.

30. Everett JN, Raymond VM, Dandapani M, et al. Screening for germline mismatch repair mutations following diagnosis of sebaceous neoplasm. JAMA Dermatol. 2014;150:1315-1321.

31. Roberts ME, Riegert-Johnson DL, Thomas BC, et al. A clinical scoring system to identify patients with sebaceous neoplasms at risk for the Muir-Torre variant of Lynch syndrome. Genet Med. 2014;16: 711-716.

32. Plocharczyk EF, Frankel WL, Hampel H, Peters SB. Mismatch repair protein deficiency is common in sebaceous neoplasms and suggests the importance of screening for lynch syndrome. Am J Dermatopathol. 2013;35:191-195.

33. Dores GM, Curtis RE, Toro JR, Devesa SS, Fraumeni JF Jr. Incidence of cutaneous sebaceous carcinoma and risk of associated neoplasms: insight into Muir-Torre syndrome. Cancer 2008. 113(12):3372-81.

34. Mojtahed A, Schrijver I, Ford JM, Longacre TA, Pai RK. A twoantibody mismatch repair protein immunohistochemistry screening approach for colorectal carcinomas, skin sebaceous tumors, and gynecologic tract carcinomas. Mod Pathol. 2011;24(7):1004-1014.

35. Naeem R, Lux ML, Huang SF, Naber SP, Corson JM, Fletcher JA. Ring chromosomes in dermatofibrosarcoma protuberans are composed of interspersed sequences from chromosomes 17 and 22. Am J Pathol. 1995;147(6):1553-1558.

36. Poland KS, Shardy DL, Azim M, et al. Overexpression of ZNF342 by juxtaposition with MPO promoter/enhancer in the novel translocation $\mathrm{t}(17 ; 19)(\mathrm{q} 23 ; \mathrm{q} 13.32)$ in pediatric acute myeloid leukemia and analysis of ZNF342 expression in leukemia. Genes Chromosomes Cancer. 2009;48(6):480-489.

37. Simon MP, Pedeutour F, Sirvent N, et al. Deregulation of the platelet-derived growth factor $\mathrm{B}$-chain gene via fusion with collagen gene COL1A1 in dermatofibrosarcoma protuberans and giant-cell fibroblastoma. Nat Genet. 1997;15(1):95-98. 
38. Sirvent N, Maire G, Pedeutour F. Genetics of dermatofibrosarcoma protuberans family of tumors: from ring chromosomes to tyrosine kinase inhibitor treatment. Genes Chromosomes Cancer. 2003;37(1):1-19.

39. Rutkowski P, Wozniak A, Switaj T. Advances in molecular characterization and targeted therapy in dermatofibrosarcoma protuberans. Sarcoma. 2011;2011:959132.

40. Rutkowski P, Van Glabbeke M, Rankin CJ, et al. Imatinib mesylate in advanced dermatofibrosarcoma protuberans: pooled analysis of two phase II clinical trials. J Clin Oncol. 2010;28(10):1772-1779.

41. Salgado R, Llombart B, M Pujol R, et al. Molecular diagnosis of dermatofibrosarcoma protuberans: a comparison between reverse transcriptase-polymerase chain reaction and fluorescence in situ hybridization methodologies. Genes Chromosomes Cancer. 2011;50(7):510-517.

42. Papp G, Mihály D, Sápi Z. Unusual signal patterns of break-apart FISH probes used in the diagnosis of soft tissue sarcomas. Pathol Oncol Res. 2017;23(4):863-871.

43. Ha SY, Lee SE, Kwon MJ, et al. PDGFB rearrangement in dermatofibrosarcoma protuberans: correlation with clinicopathologic characteristics and clinical implications. Hum Pathol. 2013;44(7):1300-1309.

44. Karanian M, Perot G, Coindre JM, Chibon F, Pedeutour F, Neuville A. Fluorescence in situ hybridization analysis is a helpful test for the diagnosis of dermatofibrosarcoma protuberans. Mod Pathol. 2015; 28(2):230-237.
45. Enzinger FM. Clear-cell sarcoma of tendons and aponeuroses. An analysis of 21 cases. Cancer. 1965;18:1163-1174.

46. Chung EB, Enzinger FM. Malignant melanoma of soft parts. A reassessment of clear cell sarcoma. Am J Surg Pathol. 1983;7(5):405-413.

47. Graadt van Roggen JF, Mooi WJ, Hogendoorn PC. Clear cell sarcoma of tendons and aponeuroses (malignant melanoma of soft parts) and cutaneous melanoma: exploring the histogenetic relationship between these two clinicopathological entities. J Pathol. 1998;186(1):3-7.

48. Takahira T, Oda Y, Tamiya S, et al. Alterations of the p16INK4a/p14ARF pathway in clear cell sarcoma. Cancer Sci. 2004;95(8):651-655.

49. Segal NH, Pavlidis $P$, Noble WS, et al. Classification of clear-cell sarcoma as a subtype of melanoma by genomic profiling. J Clin Oncol. 2003;21(9):1775-1781.

How to cite this article: Vidal $\mathrm{Cl}$, Armbrect EA, Andea AA, et al. Appropriate use criteria in dermatopathology: Initial recommendations from the American Society of Dermatopathology. J Cutan Pathol. 2018;45:563-580. https://doi. org/10.1111/cup.13142 